\title{
Peltidiphonte gen. n., a new taxon of Laophontidae (Copepoda: Harpacticoida) from coral substrates of the Indo-West Pacific Ocean
}

\author{
Hendrik Gheerardyn ${ }^{1, *}$, Frank Fiers ${ }^{2}$, Magda Vincx ${ }^{1} \&$ Marleen De Troch ${ }^{1}$ \\ ${ }^{1}$ Marine Biology Section, Ghent University, Sterre complex - Building S8, Krijgslaan 281, B-9000, Gent, Belgium \\ ${ }^{2}$ Section of Recent Invertebrates, Royal Belgian Institute of Natural Sciences, Vautierstraat 29, B-1000, Brussel, Belgium \\ (*Author for correspondence: Fax: +32-92648598; E-mail: hendrik.gheerardyn@ugent.be)
}

Received 23 December 2004; in revised form 10 May 2005; accepted 2 June 2005

Key words: Copepoda, Harpacticoida, Laophontidae, Peltidiphonte gen. n., Indo-West Pacific, dead coral substrates

\begin{abstract}
A new genus of the harpacticoid family Laophontidae is described and named Peltidiphonte gen. n. Eight new species are assigned to this genus; they were collected from different locations in the Indo-West Pacific Ocean, including the Comoros, the Kenyan coast, the Red Sea, the Andaman Islands, the northern coast of Papua New Guinea, the Solomon Islands and the northeastern coast of Australia. Most of the specimens were collected from dead coral substrates, suggesting a close affinity between the members of the new genus and this substrate. Peltidiphonte gen. n. can easily be discriminated from other genera of the family by the extremely depressed body and by the shape of the antennule, bearing two (or three) processes on the first segment and a hook-like process along the outer margin of the second segment. An identification key for the new genus is provided.
\end{abstract}

\section{Introduction}

Harpacticoid copepods show a high level of habitat specificity and adaptation to their environment (Hicks \& Coull, 1983; Huys \& Boxshall, 1991), resulting in a high diversity of body forms as classified by Noodt (1971) and Coull (1977).

The speciose family of Laophontidae comprises a large number of these body forms, including fusiform prehensile (e.g. Esola Edwards, 1891), cylindrical (e.g. Wellsiphontina Fiers, 1991), vermiform (e.g. Afrolaophonte Chappuis, 1960) and compressed (e.g. Robustunguis Fiers, 1992). This variety in body shapes reflects differences in ecology and (micro) habitat preference within the Laophontidae (e.g. epibenthic, interstitial) (Hicks \& Coull, 1983).

Meiobenthos samples from dead coral substrates yielded several new species of Laophontidae which belong to an unknown genus. Within the
Laophontidae, the newly established genus is well defined by its conspicuous, dorso-ventrally flattened body form.

\section{Material and methods}

During intensive sampling campaigns in the IndoWest Pacific Ocean (Andaman Islands: 1983; Australia: 1984; Comoros: 1981, 1985; Kenya: 2002; Papua New Guinea: 1977, 1978, 1979, 1981, 1982; Red Sea: 1983, 1986; Solomon Islands: 1982), meiofauna samples were collected from various dead coral substrates (ranging from coral sand, fine coral gravel and coral rubble to large coral fragments). All samples were taken in the tidal and subtidal zone down to a depth of $84 \mathrm{~m}$. Epifauna from coral fragments and coral rubble were rinsed off over a $1 \mathrm{~mm}$ and a $38 \mu \mathrm{m}$ sieve. Samples from coral gravel were obtained by 
decanting the coral gravel (ten times) over a $38 \mu \mathrm{m}$ sieve. Shortly after collection, buffered formaldehyde was added to a final concentration of $4 \%$.

In the laboratory, samples were rinsed over a $1 \mathrm{~mm}$ sieve with a jet of freshwater, then decanted ten times over a $38 \mu \mathrm{m}$ sieve, centrifuged three times with Ludox HS40 (specific density 1.18), and finally stained with Rose Bengal. Meiofauna was sorted and counted at the higher taxon level using a Wild M5 binocular. Harpacticoid copepods were stored in $75 \%$ ethanol.

Dissected parts of the specimens were mounted in glycerine. Preparations were sealed with insulating varnish. Observations and drawings were made on a light microscope (Leica DM LS) equipped with a drawing tube. In toto specimens are stored in $75 \%$ neutralised ethanol. Type specimens are deposited in the Invertebrate Collections of the Royal Belgian Institute of Natural Sciences (KBIN) (Brussels, labelled COP). Scale bars in figures are indicated in $\mu \mathrm{m}$.

The descriptive terminology of Huys et al. (1996) is adopted. Abbreviations used in the text are: A1, antennule; A2, antenna; ae, aesthetasc; exp, exopod; enp, endopod; P1-P6, first to sixth thoracopod; $\exp (\mathrm{enp})-1(2,3)$ to denote the proximal (middle, distal) segment of a ramus.

\section{Systematics}

Family Laophontidae T. Scott, 1905

Subfamily Laophontinae T. Scott, 1905 sensu Huys \& Lee, 2000

Genus Peltidiphonte Gheerardyn \& Fiers gen. n.

\section{Diagnosis}

Laophontidae. Body depressed to strongly depressed. Cephalothorax flattened. Free prosomites with laterally extended, winglike pleurotergites; first urosomite with backwardly produced wings; urosomites (except anal somite) broad and winged, backwardly produced. Free prosomites as wide as cephalothorax, urosomites tapering posteriorly. Genital double-somite with transverse surface ridge dorsally and laterally, indicating original segmentation; fused ventrally. Male urosome more slender than in female urosome, with a transversal row of long spinules on the ventral surface of the third urosomite. Cephalothorax and body somites with smooth, indistinctly or distinctly serrate posterior margin. Integument of the cephalothorax partly pitted and partly covered with small denticles, or entirely pitted; integument of the prosomites and urosomites pitted, covered with small denticles, with combs of small denticles or with a combination of these structures. Rostrum fused to cephalothorax, variable in shape but always large, prominent and dorsally pitted. Anal operculum convex and more or less backwardly produced.

Antennule 6- or 7-segmented in 9 , sub-chirocer and 8-segmented in $\hat{\sigma}$; aesthetascs on segment 4 and most distal segment in 9 and on segments 5 and 8 in $\hat{0}$; segment 1 with a blunt process proximally on the dorsal surface and with a blunt or sharp, small to large process along the outer margin, with or without an additional uneven process in between; segment 2 with an outer thornlike process variable in size (small thorn to large posteriorly directed hook). Antennary exopod well-developed with 3 pinnate setae and 1 subdistal, short and naked seta. Mandibular palp small, uniramous with 1, 1, 3 setae, representing basis, exopod and endopod, respectively. Maxillule with 1 pinnate seta and 1 naked seta on coxa; basis with 1 pinnate and 2 naked seta(e); endopod represented by 3 setae; exopod with 2 setae. Maxillary syncoxa with 2 endites, lacking praecoxal one; proximal endite with comb-like claw and 1 seta; distal endite with 3 setae; endopod represented by a single seta. Maxilliped with 2 pinnate setae on syncoxa; endopodal claw unarmed, with 1 short seta at base.

Swimming legs P1-P4 with 3-segmented exopods and 2-segmented endopods; chaetotaxy of third exopodal segments of P2-P4: 123, 223 and 223 , respectively. Swimming leg setal formulae in Table 1. Male endopodites with setal formula as in ${ }^{\circ}$, without apophysis in P3. Male exopodal segments of P3 and P4 only in two species (Peltidiphonte maior sp. $\mathrm{n}$. and $P$. paracristata $\mathrm{sp}$. n.) more robust than in female. P5 with separate exopod and baseoendopod. Exopod reaching far beyond the baseoendopod, ovate to elongate in + , rectangular in $\hat{\sigma}$ and bearing 5 plumose setae. Endopodal lobe of female P5 with 4 elements: 2 strong and unipinnate spines proximally, and 2 plumose setae sub-apically and apically. Male 
Table 1. Species of Peltidiphonte gen. n. Swimming leg setal formulae

\begin{tabular}{lllllll}
\hline & P2 & & P3 & & P4 \\
\hline Peltidiphonte cristata & 0.1 .123 & 0.220 & 0.1 .223 & 0.220 & 0.1 .223 & 0.121 \\
Peltidiphonte maior & 0.1 .123 & $0.220^{*}$ & 0.1 .223 & 0.220 & 0.1 .223 & 0.121 \\
Peltidiphonte ovata & 0.1 .123 & 0.220 & 0.1 .223 & 0.220 & 0.1 .223 & 0.121 \\
Peltidiphonte paracristata & 0.1 .123 & 0.220 & 0.1 .223 & 0.220 & 0.1 .223 & 0.121 \\
Peltidiphonte rostrata & 0.1 .123 & 0.220 & 0.1 .223 & 0.120 & 0.1 .223 & 0.120 \\
Peltidiphonte furcata & 0.1 .123 & 0.120 & 0.1 .223 & 0.120 & 0.1 .223 & 0.120 \\
Peltidiphonte morovoensis & 0.1 .123 & 0.120 & 0.1 .223 & 0.120 & 0.1 .223 & 0.120 \\
Peltidiphonte andamanica & 0.1 .123 & 0.120 & 0.1 .223 & 0.110 & 0.1 .223 & 0.110 \\
\hline
\end{tabular}

*specimens with 0.120 are not rare.

baseoendopod rudimentary with 1 seta. P6 vestiges bearing 1 seta in $\%$; vestiges asymmetrical in $\hat{\sigma}$, with outer distal corner produced into cylindrical process bearing 2 setae.

Caudal rami either cylindrical, or with bulbous inner margin; seta I-II-III closely set, all naked; setae IV-V not fused.

Type species - Peltidiphonte rostrata Gheerardyn \& Fiers gen. n., sp. n.

Other species $-P$. andamanica Gheerardyn \& Fiers sp. n.; P. cristata Gheerardyn \& Fiers sp. n.; $P$. furcata Gheerardyn \& Fiers sp. n.; P. maior Gheerardyn \& Fiers sp. n.; $P$. morovoensis Gheerardyn \& Fiers sp. n.; P. ovata Gheerardyn \& Fiers sp. n.; P. paracristata Gheerardyn \& Fiers sp. n.

Etymology - The generic name is a conjunction of Peltidiidae and the suffix - phonte and refers to the depressed body shape resembling the habitus of the harpacticoid family Peltidiidae. Gender: feminine.

Peltidiphonte rostrata Gheerardyn \& Fiers gen. n., sp. n.

Type locality - Western Indian Ocean, Kenyan coast, in front of village Kanamai $\left(3^{\circ} 55^{\prime} \mathrm{S}\right.$, $39^{\circ} 47^{\prime} \mathrm{E}$ ), collected from dead coral fragments, water depth less than $0.5 \mathrm{~m}$.

Material - (a) From type locality: holotype + on 1 slide (COP 4690); allotype ô on 1 slide (COP 4691); paratypes are 2 우우 and $7 \hat{\jmath} \hat{0} \hat{~ d i s s e c t e d ~ o n ~}$ slides (COP 4692 - COP 4700), and 4 우우 and 12

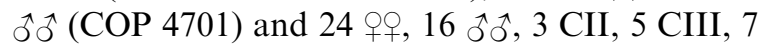
CIV and $3 \mathrm{CV}$ (COP 4702) preserved in $70 \%$ alcohol; all collected 21 February 2002. (b) Western Pacific Ocean, Papua New Guinea, different locations in Madang Province [Laing Island ( $\left.4^{\circ} 11^{\prime} \mathrm{S}, 144^{\circ} 52^{\prime} \mathrm{E}\right)$, Hansa Bay (Duangit Reef) $\left(4^{\circ} 10^{\prime} \mathrm{S}, 144^{\circ} 53^{\prime} \mathrm{E}\right)$, Chirimosh Island $\left(4^{\circ} 23^{\prime} \mathrm{S}, 145^{\circ} 14^{\prime} \mathrm{E}\right)$, Megiar Harbour ( $4^{\circ} 49^{\prime} \mathrm{S}$, $\left.145^{\circ} 46^{\prime} \mathrm{E}\right)$ ], coral sand and dead coral fragments, in tidal pools and the subtidal zone to a water

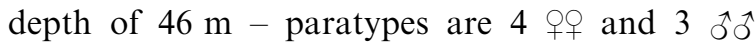
dissected on slides (COP 4703 - COP 4709), and

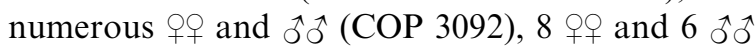

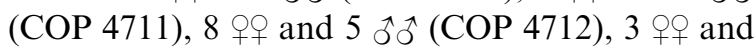
$4 \hat{\jmath} \hat{o}$ (COP 4713) and 4 우 (COP 4710) preserved in $70 \%$ alcohol; collected in June 1977, May 1979 and July 1981.

Etymology - The species name refers to the conspicuous, truncated rostrum.

\section{Description of female}

Total body length $508-585 \mu \mathrm{m} \quad(n=10$; average $=547 \mu \mathrm{m}$; measured from anterior margin of rostrum to posterior margin of caudal rami). Largest width measured at posterior margin of cephalothorax: $232 \mu \mathrm{m}$.

Rostrum (Fig. 2a) slightly longer than broad, with parallel margins and truncated at the tip; continuous with cephalothorax; with a pair of sensillae anteriorly; dorsal surface pitted; margin at the tip serrated.

Habitus (Fig. 1a). Body strongly depressed. Largest width near the posterior margin of the cephalothorax. Cephalothorax flattened, slightly broadening posteriorly. Free prosomites as wide as cephalothorax; urosome tapering posteriorly. First urosomite with posteriorly extended wings; following urosomites (except anal somite) broad and 
Key to the species of Peltidiphonte gen. n.

1. Rostrum with parallel margins and truncated at the tip

Rostrum tapering towards the tip, more or less triangular

Peltidiphonte rostrata sp. $\mathrm{n}$

Setal formula of enp-2 P2-P4: 220 or 120, 220 and 121

Setal formula of enp-2 P2-P4 different

3. Caudal rami 2.5 times as long as wide.

Posterolateral angles of the cephalothorax extended into sharp points.

Large (total body length: + : 505-600 $\mu \mathrm{m}$, ${ }^{\star}: 451-590 \mu \mathrm{m}$ ) animals

Caudal rami 2 times as long as wide at the most.

Peltidiphonte maior sp. $\mathrm{n}$.

Posterolateral angles of the cephalothorax not extended.

Smaller (total body length: o: 333-531 $\mu \mathrm{m}$, s: 286-518 $\mu \mathrm{m}$ ) animals

4. Process along the outer margin of segment 1 of A1 large (length is approx.

$2 / 3$ of the width of segment 1) and sharp in female, smaller and sharp in male.

Anterior and posterior part of the genital double-somite of the female equally wide.

Distinctly protruding anal operculum. Inner margin of the caudal rami distinctly convex

Peltidiphonte ovata sp. n.

Process along the outer margin of segment 1 of A1 rather small (length is approx.

$1 / 3$ of the width of segment 1 ) and blunt.

Anterior part of the genital double-somite of the female less wide than posterior part.

Anal operculum not protruding.

Inner margin of the caudal rami straight or slightly undulating

5. Inner margin of caudal rami undulating. No sexual dimorphism in exopods of P3-P4

Inner margin of caudal rami straight. Sexual dimorphism in exopods of P3-P4

Peltidiphonte cristata sp. n.

Peltidiphonte paracristata $\mathrm{sp} . \mathrm{n}$.

6. Setal formula of enp-2 P2-P4: 120, 110, 110. Endopods of P2-P4 very compact, not reaching beyond the corresponding exp-1.

Compact caudal rami (length-width ratio: 1.3)

Setal formula of enp-2 P2-P4: 120, 120, 120.

Peltidiphonte andamanica sp. $\mathrm{n}$.

Endopod of P2 reaching beyond middle of exp-2; endopod of P3 only

slightly longer than exp-1; endopod of $\mathrm{P} 4$ as long as exp-1.

Caudal rami not compact (length-width ratio $>1.3$ )

7. Caudal rami 3 times as long as wide. Posterolateral angles of

the cephalothorax extended into sharp points.

Female A1 7-segmented. Exopod of female P5 rounded

Caudal rami 1.7 times as long as wide. Posterolateral angles of the cephalothorax only

Peltidiphonte furcata sp. n.

slightly extended and posteriorly directed. Female A1 6-segmented.

Exopod of female P5 ovate

Peltidiphonte morovoensis sp. $\mathrm{n}$. 


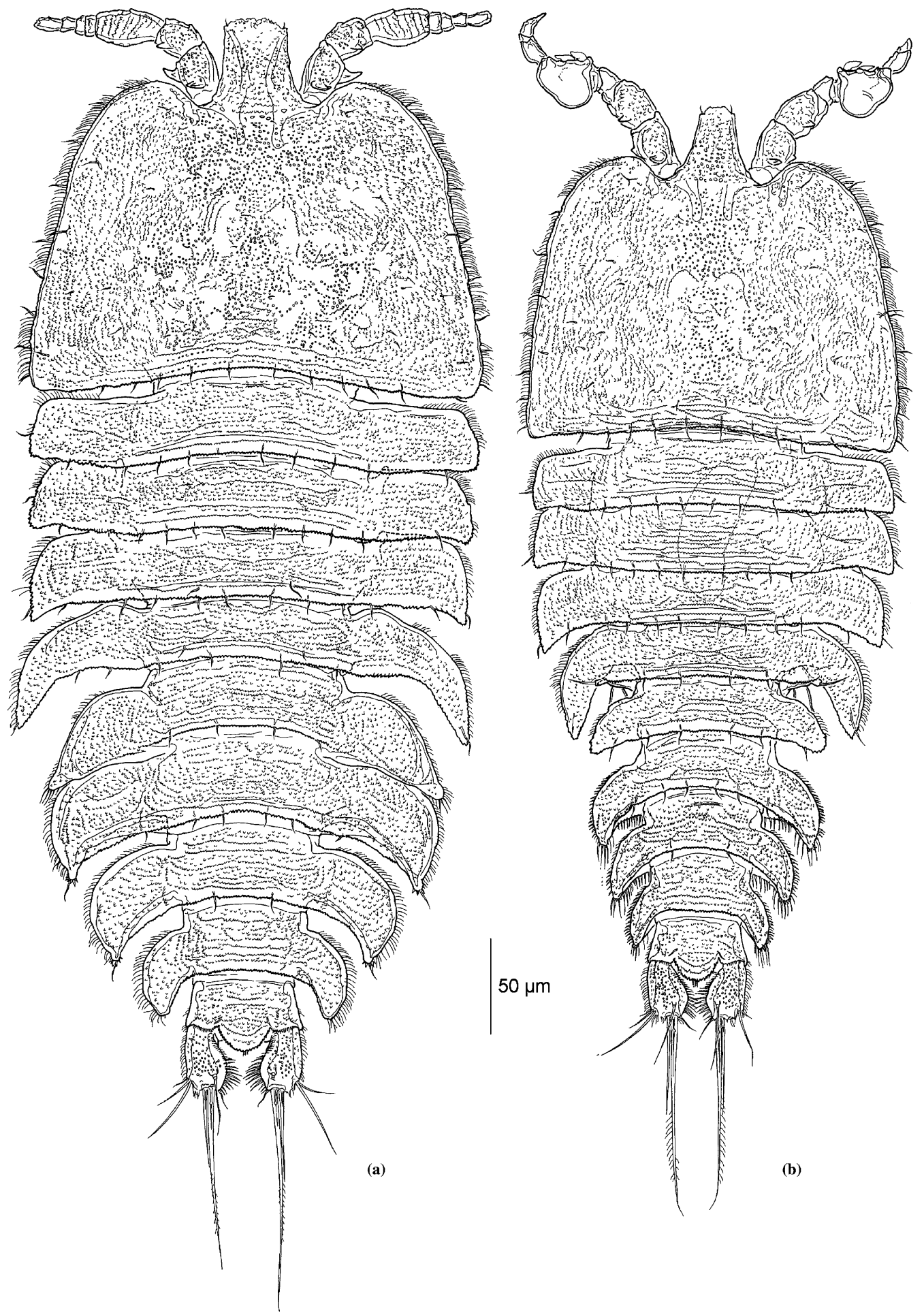

Figure 1. Peltidiphonte rostrata sp. n. (a) female habitus, dorsal; (b) male habitus, dorsal. 
winged, posteriorly extended. Second and third urosomite fused to form genital double-somite. Genital double-somite with transverse surface ridge dorsally and laterally, indicating original segmentation; fused ventrally.

Integument of the cephalothorax medially pitted and laterally with small denticles; having medially a symmetrical pattern of smooth areas; regularly ornamented with small sensillae. Posterodorsal margins of cephalothorax and somites serrate. Surface of pleurotergites with a pattern of transversally arranged small denticles. Anal somite bearing dorsally small denticles and some pits. Anal operculum crescentic with serrate margin and flanked by 2 sensillae. Caudal rami pitted dorsally. Posterodorsal margins of cephalothorax and free somites (except penultimate urosomite) bearing a number of small sensillae of which the number decreases posteriorly.

Ventral surface (Fig. 5d) of the genital doublesomite smooth, except for some median striae; of the following two urosomites smooth. Ventral surface of anal somite hairy laterally and smooth medially. Ventral surface of caudal rami hairy. Posteroventral margin of genital double-somite smooth medially, hairy along some distance of lateral side; posteroventral margins of following two urosomites with a row of strong spinules medially and hairy along the lateral sides.

Caudal rami (Fig. 5b) 1.6 times as long as wide; having a convex inner and a straight outer margin; several spinular rows ventrally and along inner margin. Setae I, II and III inserted in distal fourth of outer margin; seta I naked, shortest; setae II and III naked; setae IV and V both pinnate; seta VI naked and small; seta VII implanted in the distal fourth.

Antennule (Fig. 2a) seven-segmented; outwardly directed; majority of setae long and slender; segment 1-4 dorsally pitted and with small denticles, ventrally smooth; segment 5-7 smooth. Segment 1 dorsally with blunt thorn on proximal half; the outer margin bearing a rather large thorn, with an uneven process dorsally from it; spinular rows along inner and distal margin. Segment 2 with an outer small thorn. Segment 3 longest; outer margin convex and densely covered with fine spinules. Armature formula: I-1, II-9, III-7, IV-2 + ae, V-1, VI-2, VII-9 + ae.
Antenna (Fig. 3f). Coxa with cluster of spinules on abexopodal side. Allobasis with 1 short and unipinnate abexopodal seta. Exp unisegmented with 3 sub-equal pinnate setae and 1 subdistal, short and naked seta. Enp with 2 rows of spinules and 2 subapical frills; with following armature: subapically 2 spines and a slender seta, apically 1 long robust spine, 1 small clawlike spine, 3 geniculate setae (the outermost pinnate) and 1 slender seta.

Mandible (Fig. 3a, b). Gnathobase well developed. Biting edge formed by several blunt teeth and a seta. Surface smooth, except for some spinules along the outermost margin. Palp uniramous; endopod and exopod represented by 3 and 1 smooth seta(e), respectively. Medial seta plumose.

Maxillule (Fig. 3c). Praecoxa with a rather slender arthrite; bearing a row of long spinules on posterior surface of arthrite; medial margin furnished with 8 spines. Coxal endite with 1 pinnate seta and 1 slender naked seta. Basal endite with 3 setae (1 pinnate, 2 bare). Endopod obsolete, represented by 3 setae. Exopod 1-segmented with 2 apical setae.

Maxilla (Fig. 3d). Syncoxa with a row of long spinules along distal outer edge and 2 rows of small spinules on posterior surface; with 2 endites. Proximal endite with comb-like claw and 1 seta; distal one with 3 setae. Allobasis drawn out into strong, slightly curved, distally pinnate claw with 2 setae. Endopod obsolete, represented by a single seta.

Maxilliped (Fig. 3e). Syncoxa with 2 pinnate setae and two or three rows of spinules. Basis with 2 to 3 spinules on outer margin. Endopod clawshaped, unarmed, with short naked seta at base.

P1 (Fig. 4a). Coxa cylindrical with two rows of spinules. Basis with 1 pinnate seta along outer margin; medial seta arising in middle of anterior surface; long spinules on anterior surface, along inner and outer margin; 1 anterior tube pore near articulation with coxa. Exp-1 with 1 unipinnate outer spine; exp-2 with 1 naked outer spine; exp-3 with 2 naked outer spines and two geniculate apical setae. Enp-1 with long spinules along inner margin; enp-2 with 1 strong, smooth claw and 1 minute, naked accessory seta.

P2-P4 (Fig. 4b-d). Setal formula in Table 1. Exopodites 3-segmented and endopodites 2-segmented. Prae-coxae triangular with an outer row 

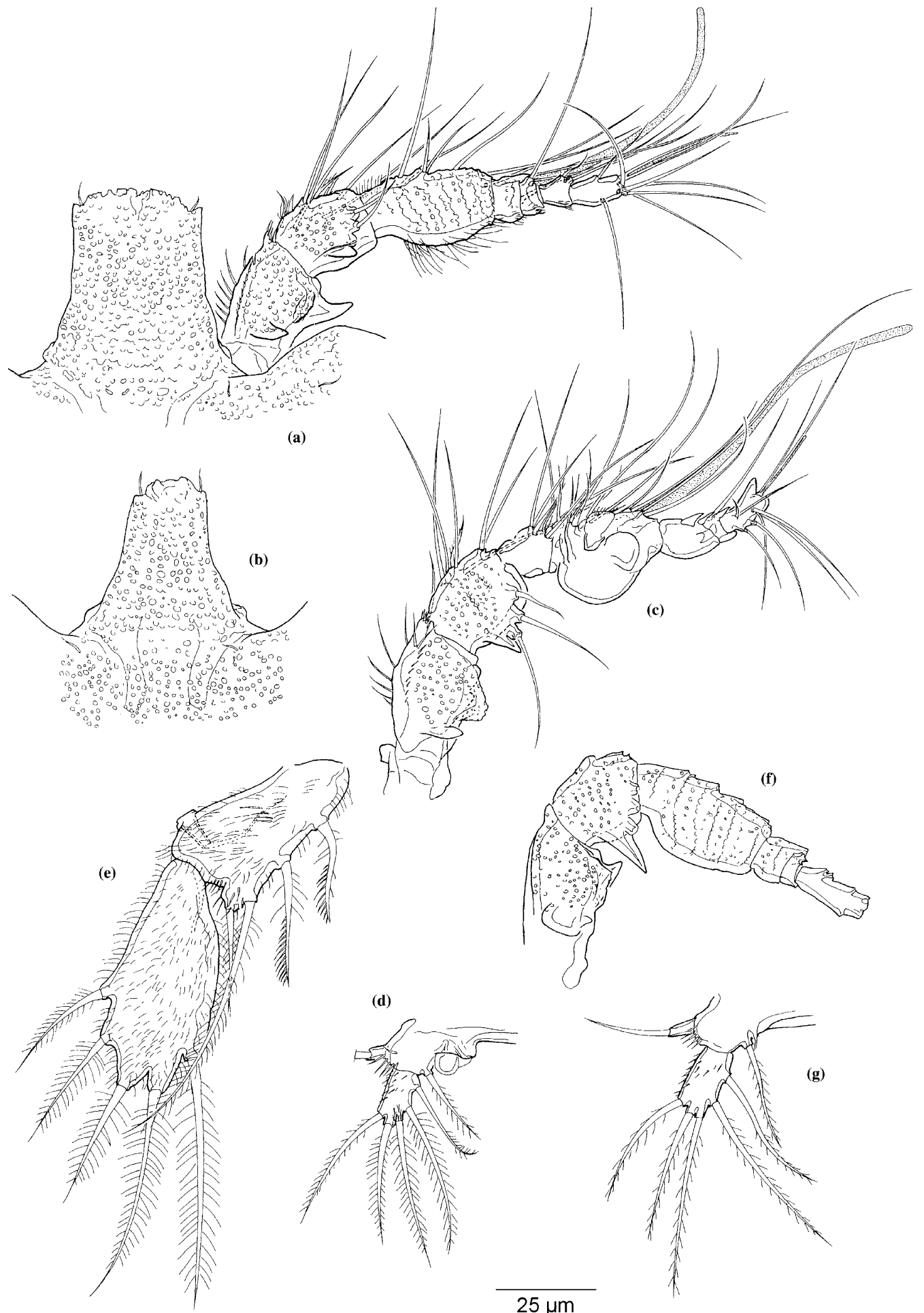

(d)
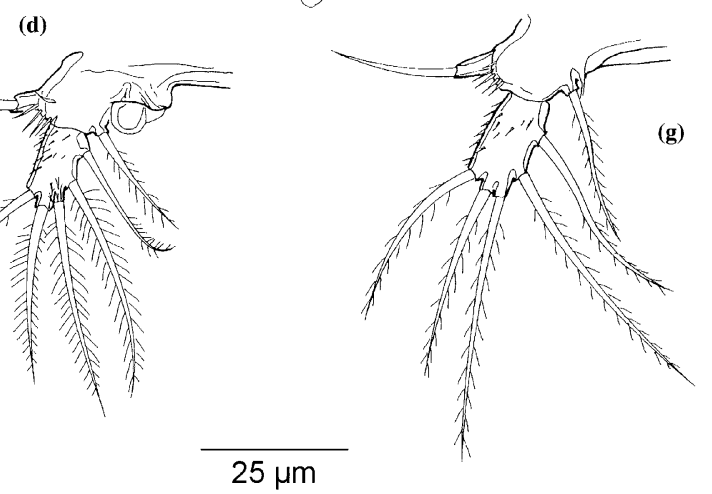

Figure 2. Peltidiphonte rostrata sp. n. (a) female rostrum and antennule, dorsal; (b) male rostrum, dorsal; (c) male antennule, dorsal; (d) male P5, anterior; (e) female P5, anterior; (f) female antennule (paratype, armature omitted), dorsal; (g) male P5 (paratype), anterior. 


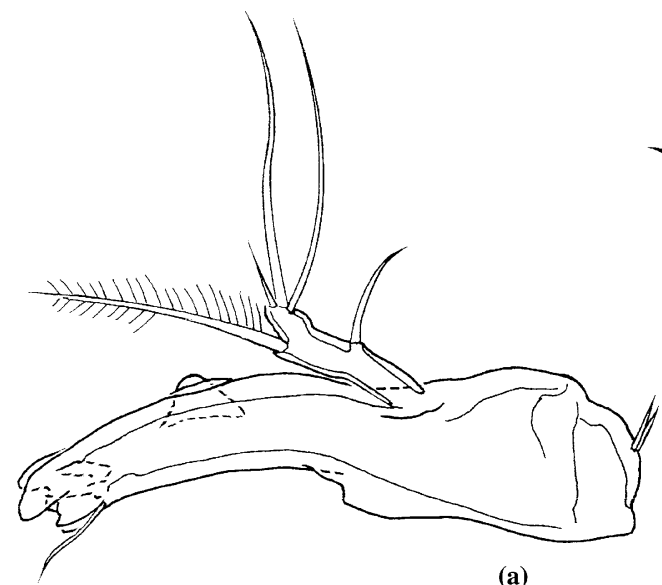

(a)
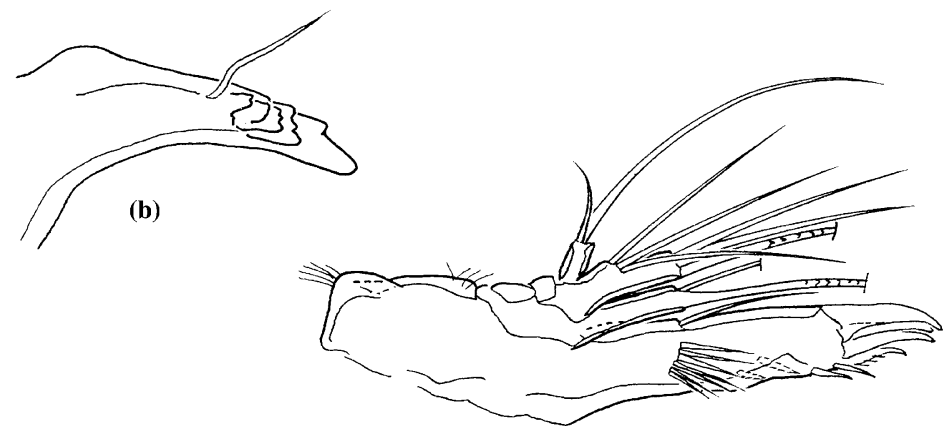

(c)
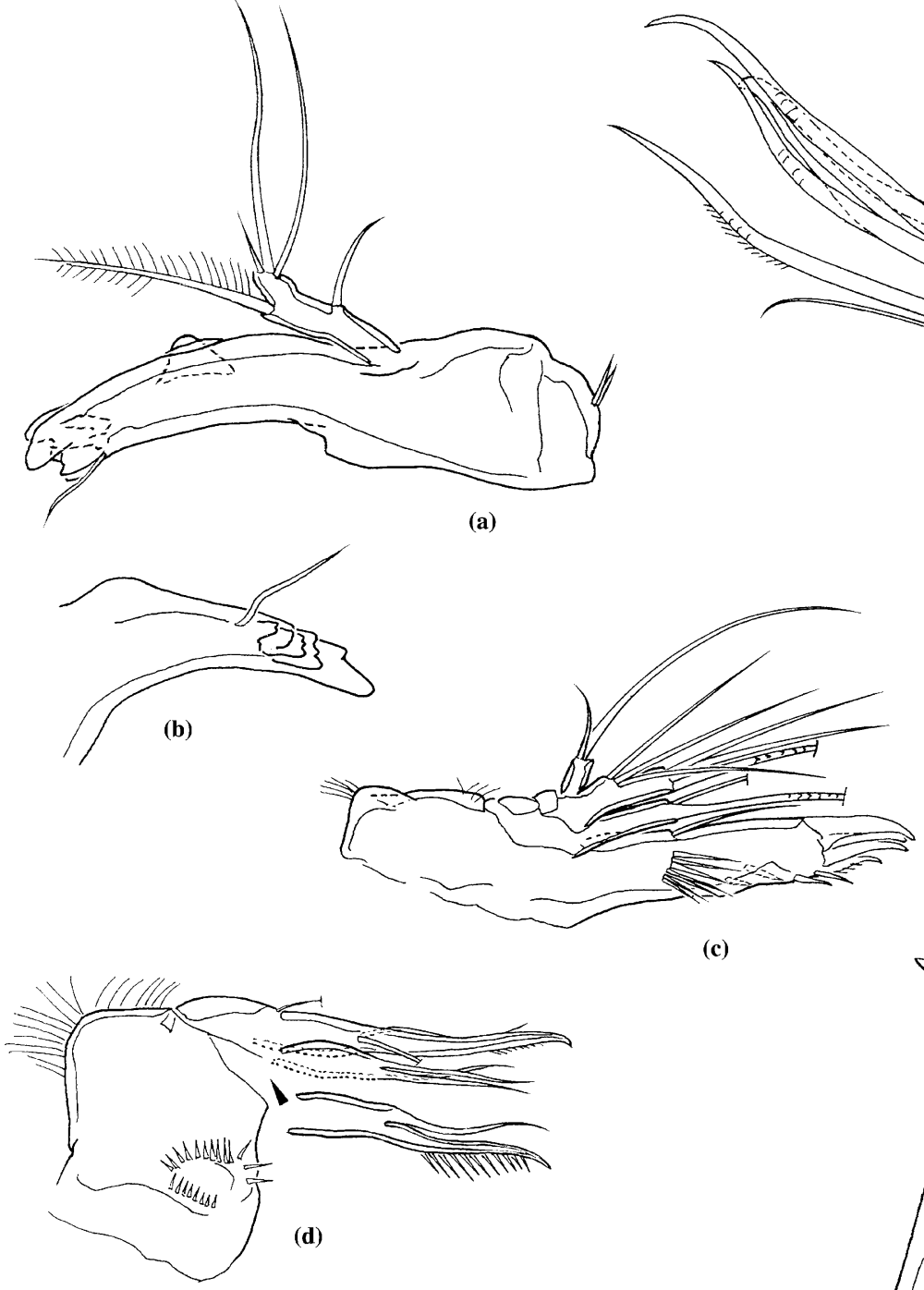


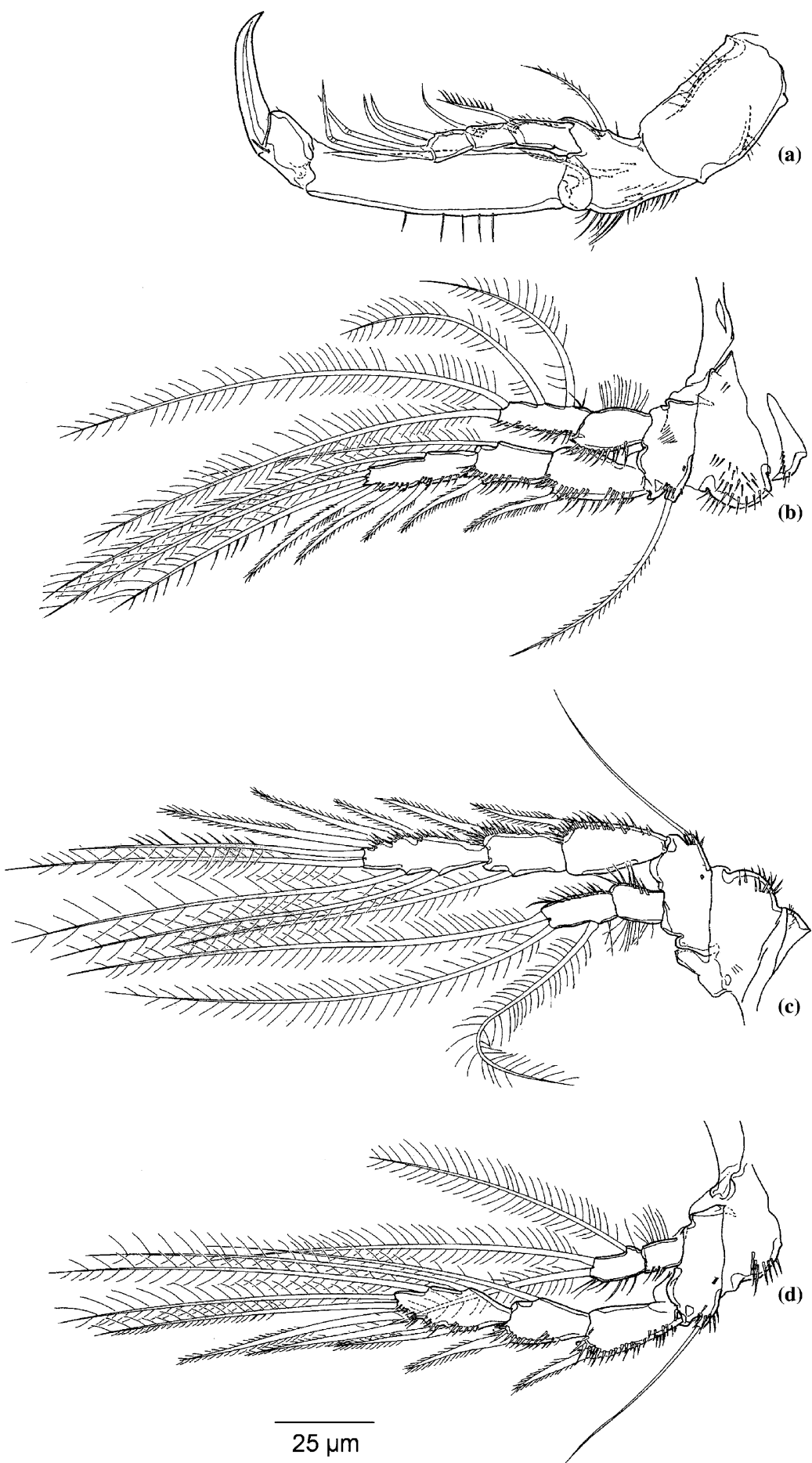

Figure 4. Peltidiphonte rostrata sp. n. (a) female P1, posterior; (b) female P2, anterior; (c) female P3, anterior; (d) female P4, anterior. 
of small spinules. Coxae with outwards directed spinules on anterior surface. Bases with a spinular row near the insertion place of the basal seta and 1 tube pore on anterior surface. Outer margin of basis with long, slender, pinnate (P2) or naked (P3-P4) seta. Endopodite P2 reaching beyond the middle of the second exopodal segment. Endopodite P3 only slightly longer than the first exopodal segment. Endopodite P4 as long as the first exopodal segment. Segments of endopods and exopods with pattern of spinules as figured.

P5 (Fig. 2e) with separate exopod and baseoendopod; both anteriorly densely covered with spinules as figured. Basal seta arising from a long cylindrical setophore (recurved in illustration). Proximal spines of endopodal lobe strong and armed as figured; sub-apical and apical seta plumose. Exopodite reaching far beyond the baseoendopod; ovate; about 2 times as long as wide; bearing 5 plumose setae, closely set in distal region.

P6 vestiges (Fig. 5d) bearing 1 seta. Copulatory pore minute.

\section{Description of male}

Total body length 419-494 $\mu \mathrm{m} \quad(n=10$; average $=466 \mu \mathrm{m}$; measured from anterior margin of rostrum to posterior margin of caudal rami). Largest width measured at posterior margin of cephalothorax: $192 \mu \mathrm{m}$.

Rostrum (Fig. 2b) remarkably less wide than in female, tapering towards the tip, but ornamented as in female.

Habitus (Figs. 1b, 5a). Smaller and more slender than female. Second and third urosomite fully separated. Urosome remarkably slender than female urosome. Ventral surface of the third urosomite with a transversal median row of spinules. Posteroventral margins of third to fifth urosomite bearing a row of strong spinules.

Antennule (Fig. 2c) eight-segmented; subchirocer. Segment 1 dorsally with blunt thorn on proximal half; bearing along the outer margin a very small, blunt thorn (unlike the female), with an uneven process dorsally from it. Segment 2 as in female. Armature formula: I-1, II-10, III-6, IV-2, V-12 (?) + ae, VI-0, VII-1, VIII-9 + ae.

Mouthparts and $\mathrm{P} 1-\mathrm{P} 4$ as in female.

P5 (Fig. 2d). Endopodal lobe of baseoendopod obsolete; bearing one plumose seta with a hyaline structure medially next to it. Basal part with an outer naked seta arising from a setophore. Outer margin bearing some longer spinules. Exopodite oblong; about twice as long as wide, bearing five plumose setae: 1 outer, 1 apical, and 3 inner ones. Outer margin and anterior surface with spinules.

P6 vestiges (Fig. 5a) asymmetrical. One vestige functional; one vestige fused to somite. Both produced into a long cylindrical process bearing a sub-apical inner pinnate and an apical smooth seta.

Variability - Most specimens from Papua New Guinea differ in some aspects from the Kenyan material. The female A1 is 6-segmented (as a result of the fusion of the sixth and seventh segments) and the outer process on segment 2 of $A 1$ is somewhat larger (Fig. 2f). The hyaline structure on the baseoendopod of the male P5 is less developed or absent (Fig. 2g). While the posterolateral angles of the second urosomite of the male are rather rounded in the specimens from Kenya, they are sharpened (comparable to the shape of the first urosomite) in most specimens from Papua New Guinea. Finally, the teeth around the margin of the anal operculum are larger (Fig. 5c). However, the samples from Papua New Guinea included also specimens which did not show any of these differences.

Differential diagnosis - Peltidiphonte rostrata is clearly distinguished from the other species of the genus by its conspicuous, truncated rostrum with parallel margins and the rather small process along the outer margin of segment 2 of A1. All other species have a more or less triangular rostrum with a bifid tip and the process along the outer margin of segment 2 of A1 occurs as a large posteriorly directed hook. P. rostrata also has a unique setal formula within the genus.

Known range $-P$. rostrata is known from the Kenyan coast (type locality) and the northern coast of Papua New Guinea (Madang Province).

Peltidiphonte andamanica Gheerardyn \& Fiers sp. n.

Type locality - Indian Ocean, Andaman Islands, Jolly Boy Island $\left(11^{\circ} 31^{\prime} \mathrm{N}, 92^{\circ} 37^{\prime} \mathrm{E}\right)$, submerged coral reef, water depth $1-1.5 \mathrm{~m}$, coral sand between soft corals. 


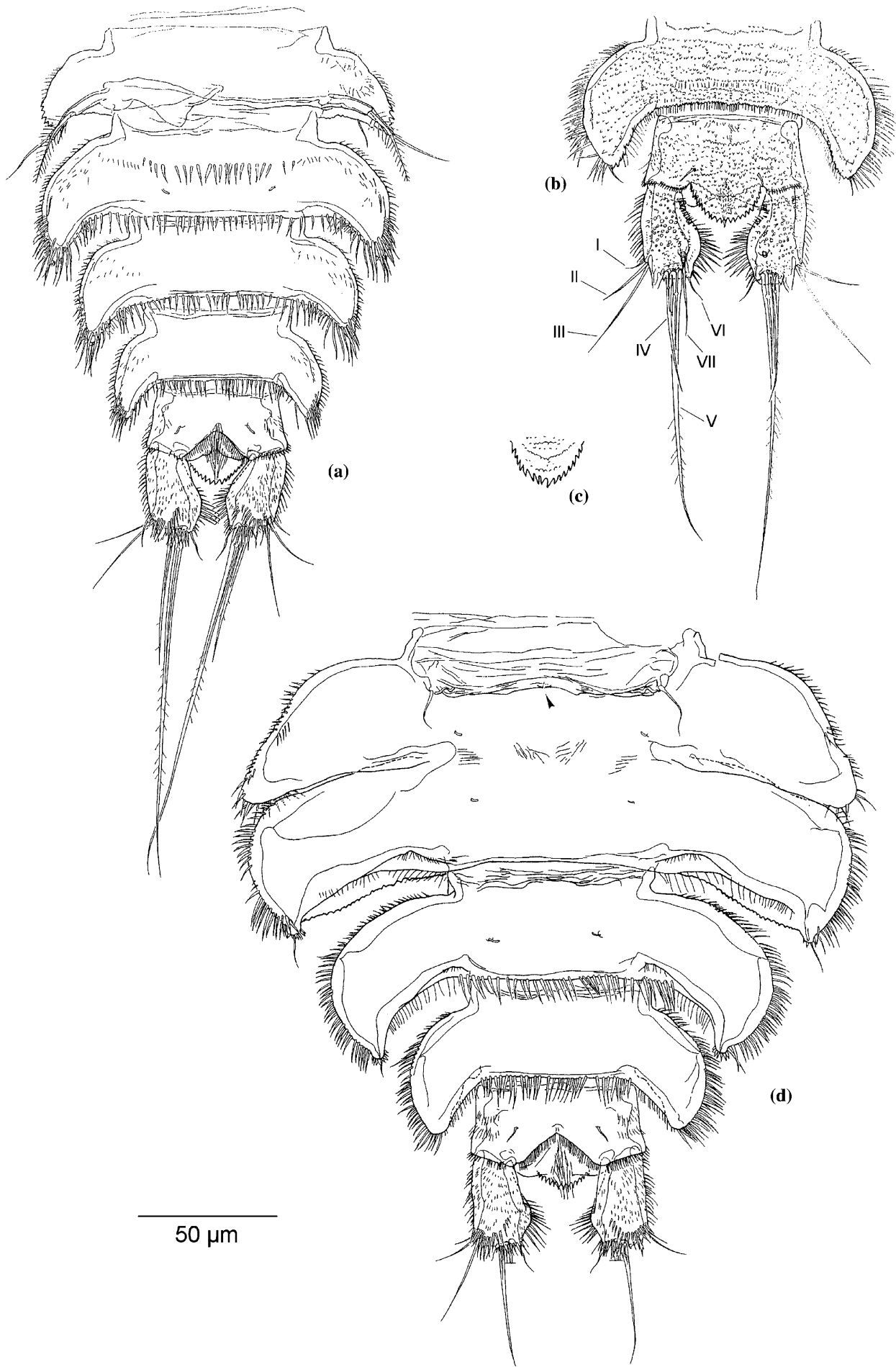

Figure 5. Peltidiphonte rostrata sp. n. (a) male urosome, ventral; (b) female anal somite and caudal rami, dorsal; (c) anal operculum (paratype), dorsal; (d) female urosome, ventral (arrow indicating copulatory pore). 
Material - From type locality: holotype 9 dissected on 1 slide (COP 2428); collected 5 April 1983.

Etymology - The species name refers to the type locality of this species.

\section{Description of female}

Total body length $400 \mu \mathrm{m}$ (measured from anterior margin of rostrum to posterior margin of caudal rami). Largest width measured at posterior margin of cephalothorax: $150 \mu \mathrm{m}$.

Rostrum (Fig. 6e) large with straight margins; rather narrow; tapering towards the bifid tip; ventral surface with distinct smooth carina, supporting the tip; integument dorsally and ventrolaterally pitted.

Habitus (Fig. 6a). Body depressed; rather elongated in dorsal view. Cephalothorax tapering slowly towards the front; slightly constricted near the middle. Pleurotergites of prosome with rounded lateral margins. First urosomite with sharp, posteriorly directed wings. Anterior part of genital double-somite somewhat narrower and with rounded margins. Following urosomites (except anal somite) broad and winged; posteriorly extended.

Dorsal integument entirely pitted. Posterodorsal margin of cephalothorax smooth; posterolateral angles lobate with a serrate margin. Posterodorsal margins of prosomites and urosomites (including both urosomites which form the genital double-somite) distinctly serrate over the entire length. Anal operculum with two parallel serrate combs and a serrate margin. Caudal rami pitted dorsally.

Ventral surface of anterior part of the genital double-somite striated. Ventral integument of the following urosomites smooth. Posteroventral margins of genital double-somite and following urosomites spinulose. Caudal rami smooth ventrally.

Caudal rami 1.3 times as long as wide; inner margin strongly convex in the second half, bearing long spinules; outer margin straight; seta I, II, III and VII implanted almost apically.

Antennule (Fig. 6b) six-segmented; segment 1-4 dorsally pitted and provided with spinules along their margins; segment 4 and 5 with a wreath of small spinules; segment 6 smooth. Segment 1 dorsally with a blunt thorn on the proximal half; the outer margin bearing a blunt thorn proximally. Segment 2 with an outer large thorn.

Mouthparts and P1-P5 (Fig. 6c, d) as in Peltidiphonte rostrata. Swimming leg setal formula in Table 1. Endopods of P2-P4 not reaching beyond the first exopodal segment; all having a compact appearance.

\section{Male unknown}

Differential diagnosis - Peltidiphonte andamanica exhibits the most reduced chaetotaxy in the genus. Enp-2 of P3-P4 bear only two setae. The segments of the legs have a compact appearance. The integument of $P$. andamanica is very densely pitted.

Known range $-P$. andamanica is known from the type locality only.

Peltidiphonte cristata Gheerardyn \& Fiers sp. n.

Type locality - Western Indian Ocean, Comores Islands, Grande Comore, $1 \mathrm{~km}$ north of Moroni $\left(11^{\circ} 42^{\prime} \mathrm{S}, 43^{\circ} 14^{\prime} \mathrm{E}\right)$, sand sample, water depth $15 \mathrm{~m}$.

Material - (a) From type locality: holotype + dissected on 1 slide (COP 2429); allotype $\sigma^{1}$ on 1 slide (COP 4655); paratypes are $1+$ and 1 ô dissected on slides (COP 4656 - COP 4657) and 19 우우, 6 ô $0^{\wedge}$ and $3 \mathrm{CV}$ (COP 2431) preserved in $70 \%$ alcohol; all collected 24 November 1985;

(b) Western Indian Ocean, Comoros, different locations on Grande Comore [Foumbouni $\left(11^{\circ} 51^{\prime} \mathrm{S}, \quad 43^{\circ} 29^{\prime} \mathrm{E}\right), \quad$ Chindini $\left(11^{\circ} 55^{\prime} \mathrm{S}\right.$, $\left.43^{\circ} 29^{\prime} \mathrm{E}\right)$ ], sand samples, different water depths (10-30 m) - paratypes are 3 ôे (COP 2432), 1 우 and 1 +CV (COP 2433), 1 ( (COP 2436), 1 (COP 2437), and 1 (COP 2438) preserved in $70 \%$ alcohol; all collected in August 1981.

Etymology - The species name refers to the transversal combs of small denticles on the pleurotergites of this species.

\section{Description of female}

Total body length 333-415 $\mu \mathrm{m}$ (measured from anterior margin of rostrum to posterior margin of caudal rami). Largest width measured at posterior margin of cephalothorax: $166 \mu \mathrm{m}$.

Rostrum (Fig. 7b) triangular with tapering margins towards the front; tip bifid; dorsal surface pitted. 


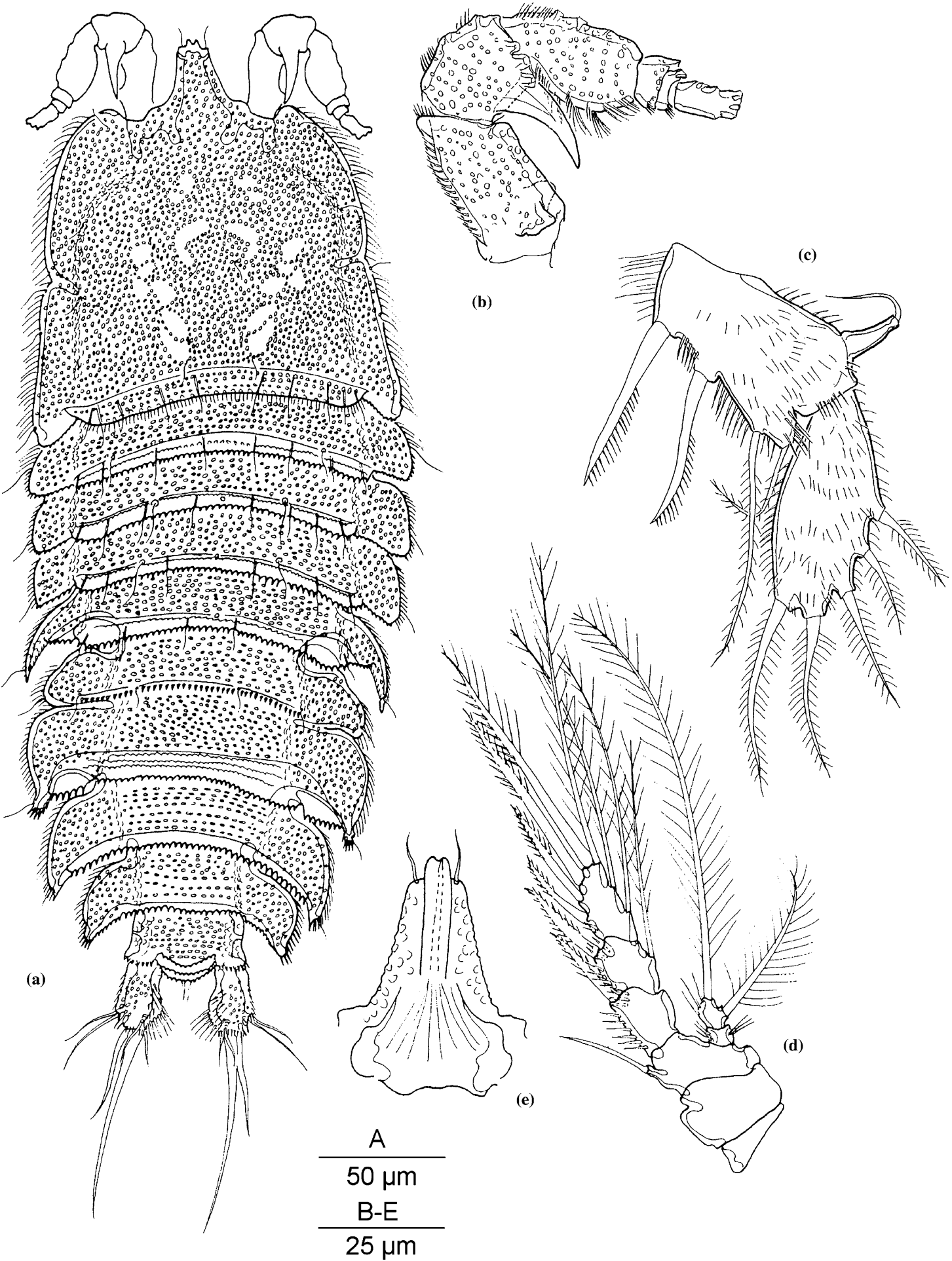

Figure 6. Peltidiphonte andamanica sp. n. (a) female habitus, dorsal; (b) female antennule (armature omitted), dorsal; (c) female P5, anterior; (d) female P4, posterior; (e) female rostrum, ventral. 


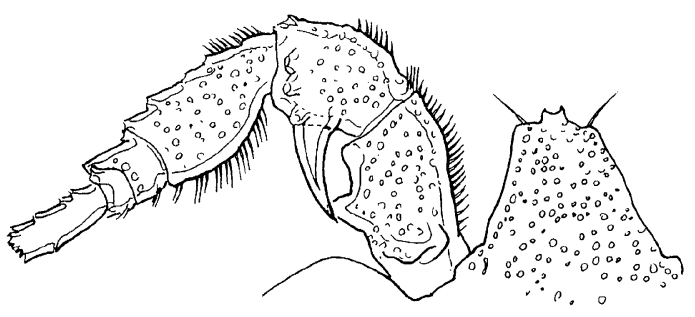

(b)
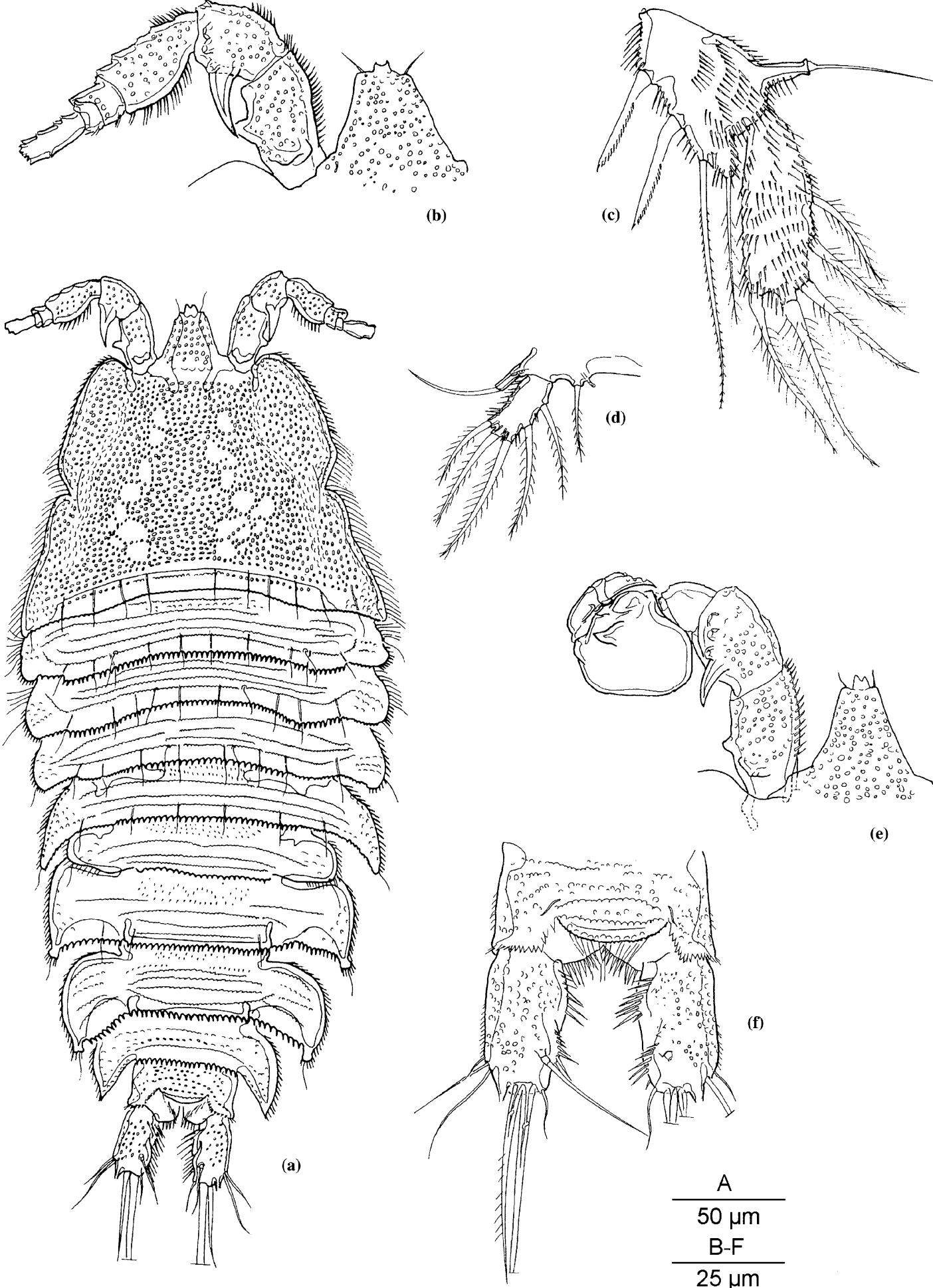

Figure 7. Peltidiphonte cristata sp. n. (a) female habitus, dorsal; (b) female rostrum and antennule (armature omitted); (c) female P5, anterior; (d) male P5, anterior; (e) male rostrum and antennule (armature omitted), dorsal; (f) female caudal rami, dorsal. 
Habitus (Fig. 7a). Largest width near posterior margin of cephalothorax. Cephalothorax tapering strongly in anterior direction; showing a distinct constriction in the middle of the lateral margin. Pleurotergites extended laterally, except for the anal somite. First urosomite, genital double-somite and following urosomites somewhat protruded in posterior direction. Anterior part of genital double-somite less wide than posterior part.

Ventral surface of genital double-somite striated. Ventral surface of following urosomites smooth. Posteroventral margins of genital doublesomite and following urosomites spinulose. Ventral surface of anal somite smooth medially, hairy laterally.

Rostrum, cephalothorax, anal somite and dorsal surface of caudal rami pitted. Pleurotergites of prosomites and urosomites with a pattern of small denticles and transversal rows of small denticles; lateral wings with more or less pits. Posterior margin of cephalothorax smooth medially, serrate laterally. Prosomites and urosomites with a distinctly serrate posterodorsal margin. Anal operculum not distinctly protruding and convex with an almost smooth margin.

Caudal rami (Fig. 7f) cylindrical and 1.7 times as long as wide. Seta I, II, III and VII implanted sub-apically. Inner margin of caudal rami undulating; outer margin straight. Inner margin furnished with two rows of long spinules.

Antennule (Fig. 7b) six-segmented; segment 14 with a pitted dorsal integument; segment 1-3 with spinules along the inner margin; segment 3-5 with spinules along the outer margin. Segment 1 proximally with a dorsal and a lateral blunt thorn. Segment 2 with a large posteriorly directed hook.

Mouthparts and P1-P4 as in Peltidiphonte rostrata. Swimming leg setal formula in Table 1.

P5 (Fig. 7c) as in Peltidiphonte rostrata. Exopodite oblong. Baseoendopod and exopod furnished densely with spinules on the surface and along the margins.

\section{Description of male}

Total body length $286-410 \mu \mathrm{m}$ (measured from anterior margin of rostrum to posterior margin of caudal rami).

Rostrum (Fig. 7e). Narrower than in female; with slightly concave margins.
Habitus and length as in the female except for the slightly more slender urosome. Ventral surface of urosomites as in type species with a transversal row of spinules on third urosomite, other urosomites smooth. Posteroventral margins of third to fifth urosomite spinulose. Posterolateral wing of second urosomite rounded.

Antennule (Fig. 7e) eight-segmented; sub-chirocer. Segment 1 and 2 as in female. Integument of other segments smooth. Segment 5 with a process on the dorsal surface. Segment 6 with a small bump on the dorsal surface.

Mouthparts and P1-P4 as in female.

P5 (Fig. 7d). Baseoendopod represented as a small strip, bearing one seta. Exopodite oblong, spinulose along the lateral margins.

Differential diagnosis - Peltidiphonte cristata shares the same leg chaetotaxy with $P$. maior, $P$. ovata and $P$. paracristata. It differs from $P$. maior in particular by the shorter caudal rami, the much smaller body size and the shape of the posterolateral angles of the cephalothorax. It differs from $P$. ovata by the tapering rostrum, the more compressed habitus, the shape of the caudal rami and the blunt outer thorn on the first segment of the antennule. The anterior part of the genital double-somite in the female of $P$. cristata is distinctly narrower than the posterior part, whereas in the female of $P$. ovata both parts are equally wide. Moreover, the anal operculum in P. ovata is distinctly protruding posteriorly. $P$. cristata is closely related to $P$. paracristata but clearly differs in the shape of the caudal rami and the absence of sexual dimorphism in the exopodites of P3 and P4.

Known range $-P$. cristata is known from the Comoros (type locality).

\section{Peltidiphonte furcata Gheerardyn \& Fiers sp. n.}

Type locality - Western Pacific Ocean, Papua New Guinea, Madang Province, Hansa Bay (Duangit Reef) $\left(4^{\circ} 10^{\prime} \mathrm{S}, 144^{\circ} 53^{\prime} \mathrm{E}\right)$, coral sand and coral rubble from the east side, water depth 40-46 m.

Material - (a) From type locality: holotype ㅇ dissected on 1 slide (COP 2439); allotype $\hat{\sigma}$ dissected on 1 slide (COP 2440); paratypes are 2 우 and 2 ôे (COP 2441) preserved in 70\% alcohol; all collected 28 May 1979; 
(b) Western Pacific Ocean, Papua New Guinea, Madang Province, Barol Beach (east of Hansa Point) (4 $\left.11^{\prime} \mathrm{S}, 144^{\circ} 54^{\prime} \mathrm{E}\right)$, coarse sand from a tidal pool - paratypes are 1 + and $1 \hat{\jmath}$ (COP 2442) preserved in 70\% alcohol; collected 23 May 1982;

Etymology - The species name refers to the long and cylindrical caudal rami of this species.

\section{Description of female}

Total body length $350-420 \mu \mathrm{m}$ (measured from anterior margin of rostrum to posterior margin of caudal rami). Largest width measured at posterior margin of cephalothorax: $135 \mu \mathrm{m}$.

Rostrum (Fig. 8e) large with straight lateral margins; triangular; tip small, prominent and bilobed; dorsal surface pitted.

Habitus (Fig. 8a). Body depressed; with a rather slender body-shape (comparing to its congeners). Cephalothorax slightly constricted near the middle; posterolateral angles extended into sharp points. Free prosomites and first urosomite with laterally directed rounded pleurites. Anterior part of genital double-somite only slightly extended. Following urosomites protruded in posterior direction. Anal somite with a convex anal operculum with an only slightly serrate margin. Caudal rami pitted dorsally.

Cephalothorax and pleurotergites pitted in a less dense pattern. Pleural integument of the somites with some incomplete pits. Posterodorsal margin of cephalothorax smooth; of the following somites serrate. Ventral surface of genital doublesomite and anterior part of the following urosomite with fine cuticular striae. Ventral surface of the following urosomites smooth. Posteroventral margins of genital double-somite and following urosomites set with long spinules.

Caudal rami laterally furnished with minute denticles and ventrally smooth; cylindrical with straight margins and 3 times as long as wide. Setae I, II and III implanted near the distal margin; seta VI short and smooth; seta VII implanted in the distal sixth.

Antennule (Fig. 8d) seven-segmented. Integument of segment 1-4 pitted dorsally, of the other segments smooth. Segment 1 proximally with a dorsal and a small lateral blunt thorn; spinulose along the inner margin. Segment 2 with a large posteriorly directed hook and long spinules along inner margin. Segment 3-6 with long and slender spinules along the outer margin.

Mouthparts and $\mathrm{P} 1-\mathrm{P} 4$ as in Peltidiphonte rostrata. Swimming leg setal formula in Table 1.

P5 (Fig. 8g). Baseoendopodite with very long spinules along the proximal inner margin and along the articulation with the exopodite; proximal spines strong and armed along one side; apical and sub-apical setae long and plumose. Exopodite ovate with long spinules along the outer margin and with 5 plumose setae.

\section{Description of male}

Total body length 330-390 $\mu \mathrm{m}$ (measured from anterior margin of rostrum to posterior margin of caudal rami).

Habitus (Fig. 8b) as in female but with a more slender urosome. Ventral surface of the third urosomite with a transversal row of spinules. Posteroventral margins of third to fifth urosomite bearing a row of spinules, which are slender in the median part of the posteroventral margin of the third and fourth urosomite.

Antennule (Fig. 8c) eight-segmented; sub-chirocer. Segment 1 and 2 as in female. Segment 3-8 devoid of integumental structures. Segment 6 with a blunt process dorsally along the outer margin.

Mouthparts and P1-P4 as in female.

P5 (Fig. 8f). Baseoendopodite represented as a small strip, bearing one seta. Exopodite oblong bearing five plumose setae.

P6 vestiges asymmetrical. One vestige functional; one vestige fused to somite. Both rami oblong; bearing two setae, inner one plumose, outer one naked.

Variability - The specimens from Barol Beach have somewhat shorter caudal rami, namely 2.2 2.6 times as long as wide. The male of Peltidiphonte furcata shows a somewhat variable chaetotaxy on the endopods of P3-P4. Some specimens have endopods which bear only 2 setae on enp-2 instead of 3.

Differential diagnosis $-P$. furcata is easily distinguishable from its congeners by the markedly tapering urosome, the long caudal rami, the posterolateral angles of the cephalothorax which are extended into sharp points, the more or less rounded exopodite of the female P5 and the slender body shape. The male of $P$. furcata has a dis- 

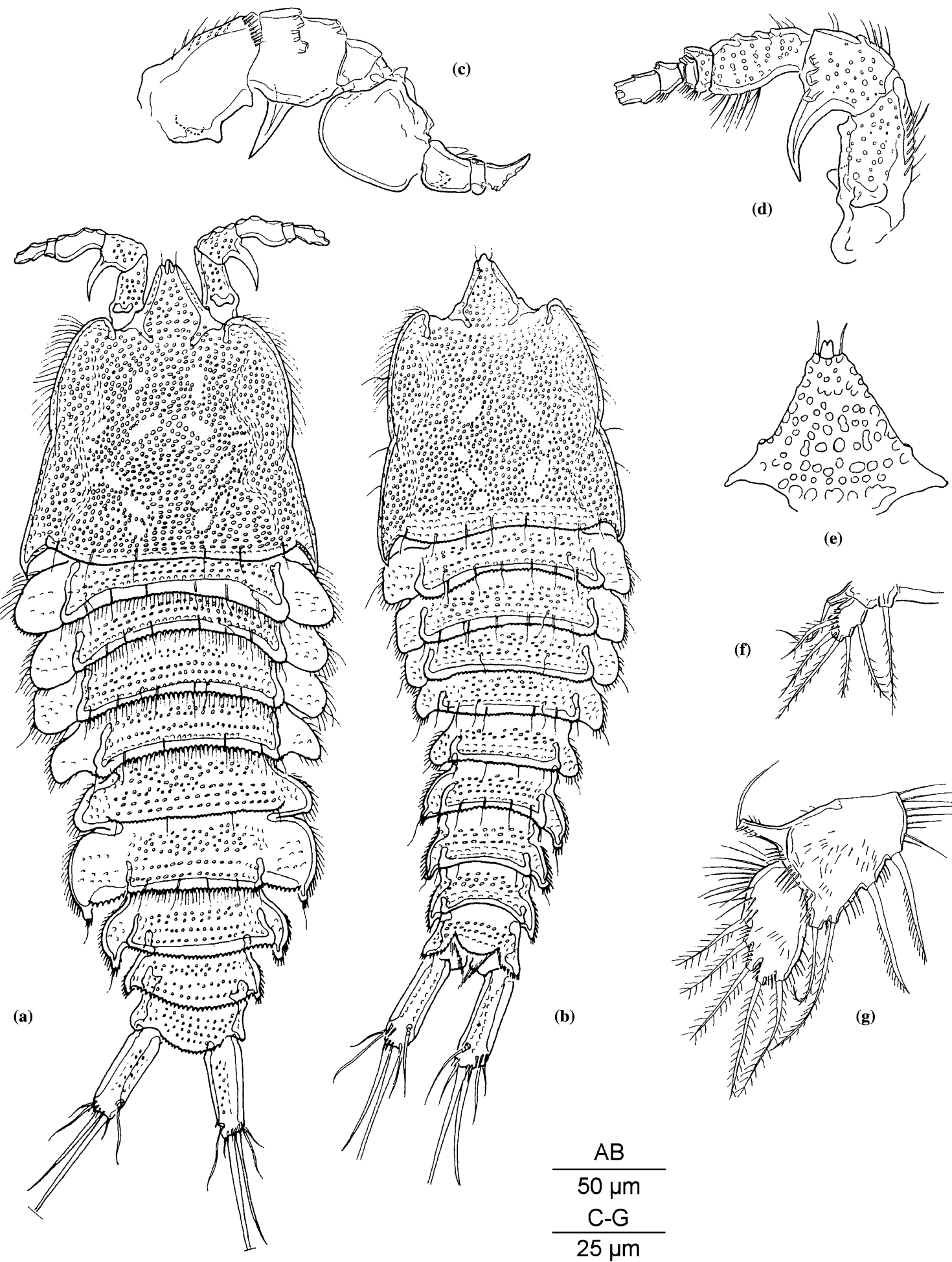

(e)
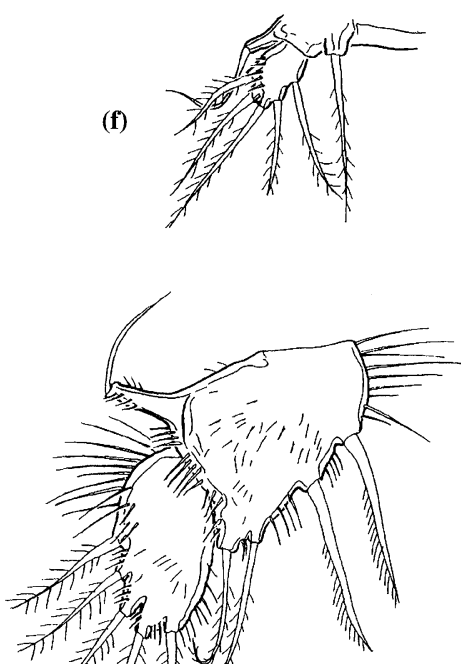

(g)

Figure 8. Peltidiphonte furcata sp. n. (a) female habitus, dorsal; (b) male habitus, dorsal; (c) male antennule (armature omitted), ventral; (d) female antennule (armature omitted), dorsal; (e) female rostrum, dorsal; (f) male P5, anterior; (g) female P5, anterior. 
tinctly slender urosome. Although the male urosome of all species of the genus is somewhat narrower than that of the female, the constriction in $P$. furcata is very conspicuous and is an important discriminating feature.

Known range $-P$. furcata is known from the northern coast of Papua New Guinea (Madang Province).

\section{Peltidiphonte maior Gheerardyn \& Fiers sp. n.}

Type locality - Western Pacific Ocean, Papua New Guinea, Madang Province, Laing Island $\left(4^{\circ} 11^{\prime} \mathrm{S}\right.$, $\left.144^{\circ} 52^{\prime} \mathrm{E}\right)$, northwestern reef flat, coarse coral sand in tidal pools.

Material - (a) From type locality: holotype $q$ dissected on 3 slides (COP 2403a-c); allotype $\hat{o}$ dissected on 2 slides (COP 2404a-b); 1 i paratype dissected on 3 slides (COP 2405a-c) and 27 paratypes (COP 1942) preserved in $70 \%$ alcohol; all collected on 8 May 1978.

(b) Western Pacific Ocean, Papua New Guinea, different locations in Madang Province [Laing Island $\left(4^{\circ} 11^{\prime} \mathrm{S}, 144^{\circ} 52^{\prime} \mathrm{E}\right)$, Legoarant Island $\left(4^{\circ} 18^{\prime} \mathrm{S}, 145^{\circ} 1^{\prime} \mathrm{E}\right)$, Kabak Plantation (east of Kumbug Bay) $\left(4^{\circ} 23^{\prime} \mathrm{S}, 145^{\circ} 9^{\prime} \mathrm{E}\right)$, Barol Beach (east of Hansa Point) $\left(4^{\circ} 11^{\prime} \mathrm{S}\right.$, $\left.144^{\circ} 54^{\prime} \mathrm{E}\right), \quad$ Podbielsky Point $\left(4^{\circ} 15^{\prime} \mathrm{S}\right.$, $\left.144^{\circ} 58^{\prime} \mathrm{E}\right)$, Talia Point $\left(4^{\circ} 18^{\prime} \mathrm{S}, 144^{\circ} 59^{\prime} \mathrm{E}\right)$, coral sand, tidal and subtidal zone to a water depth of $12 \mathrm{~m}$ - paratypes are 4 우우 and 5 주오 dissected on slides (COP 4658 - COP 4666) and numerous 우 and $\hat{\jmath} \hat{o}$ (COP $2411-$ COP 2423, COP 2425 - COP 2428) preserved in 70\% alcohol; collected in May 1977, May 1978, June 1979, July 1981, May 1982 and June 1982.

Etymology - The species name refers to the large size of this species in comparison with the other members of the genus.

\section{Description of female}

Total body length 505-600 $\mu \mathrm{m}$ (measured from anterior margin of rostrum to posterior margin of caudal rami). Largest width measured at posterior margin of cephalothorax: $238 \mu \mathrm{m}$.

Rostrum large; prominent and tapering towards the tip; lateral margins concave; dorsal surface pitted; tip bifid.

Habitus (Fig. 9a, b). Body depressed. Largest width near posterior margin of cephalothorax.
Cephalothorax flattened with curved margins and constricted in the middle. Posterolateral angles of cephalothorax extended into sharp points. Pleurotergites of free prosomites widening posteriorly, somewhat extended in posterior direction. Anterior part of genital double-somite rather small, fitting into the protruded wings of the first urosomite. Following urosomites (except anal somite) broad and winged, posteriorly extended.

Cephalothorax pitted; having a symmetrical pattern of smooth areas; posterior margin smooth but strongly serrate near the posterolateral extensions. Pleurotergites of the somites with a pattern of transversally arranged denticles. Posterodorsal margins of the somites serrate. Caudal rami densely covered with small spinules except for a small smooth strip on the dorsal surface; dorsal surface with some pits.

Ventral surface of genital double-somite striated, of the following urosomites smooth. Ventral surface of anal somite hairy laterally and smooth in the middle. Posteroventral margin of genital double-somite smooth in the middle and hairy along some distance of the lateral side; idem for the following somite but set with small spinules in the middle. Posteroventral margins of the penultimate urosomite and the anal somite with strong spinules.

Caudal rami 2.5 times as long as wide; cylindrical; having a slightly convex inner margin and a straight outer one. Seta VII implanted in the distal fourth; other setae similar to the type species.

Antennule (Fig. 9c) six-segmented (Segment 6 can have an indistinct transverse suture). Segment 1 with a dorsal and a lateral blunt thorn. Segment 2 with a large posteriorly directed hook. Dorsal surface of segment 1 and 2 strongly pitted and set with long spinules along the inner margin. Segment 3-5 with spinules on the dorsal surface and along the outer margin.

Mouthparts and $\mathrm{P} 1-\mathrm{P} 4$ as in Peltidiphonte rostrata. Swimming leg setal formula in Table 1. Anterior surfaces of the rami are clothed with somewhat longer spinules comparing to the type species (Fig. 10a, b).

P5 (Fig. 10e). Proximal baseoendopodal spines strong, armed along one side; sub-apical and apical setae plumose. Exopodite ovate bearing five plumose setae. Surface of baseoendopodite 


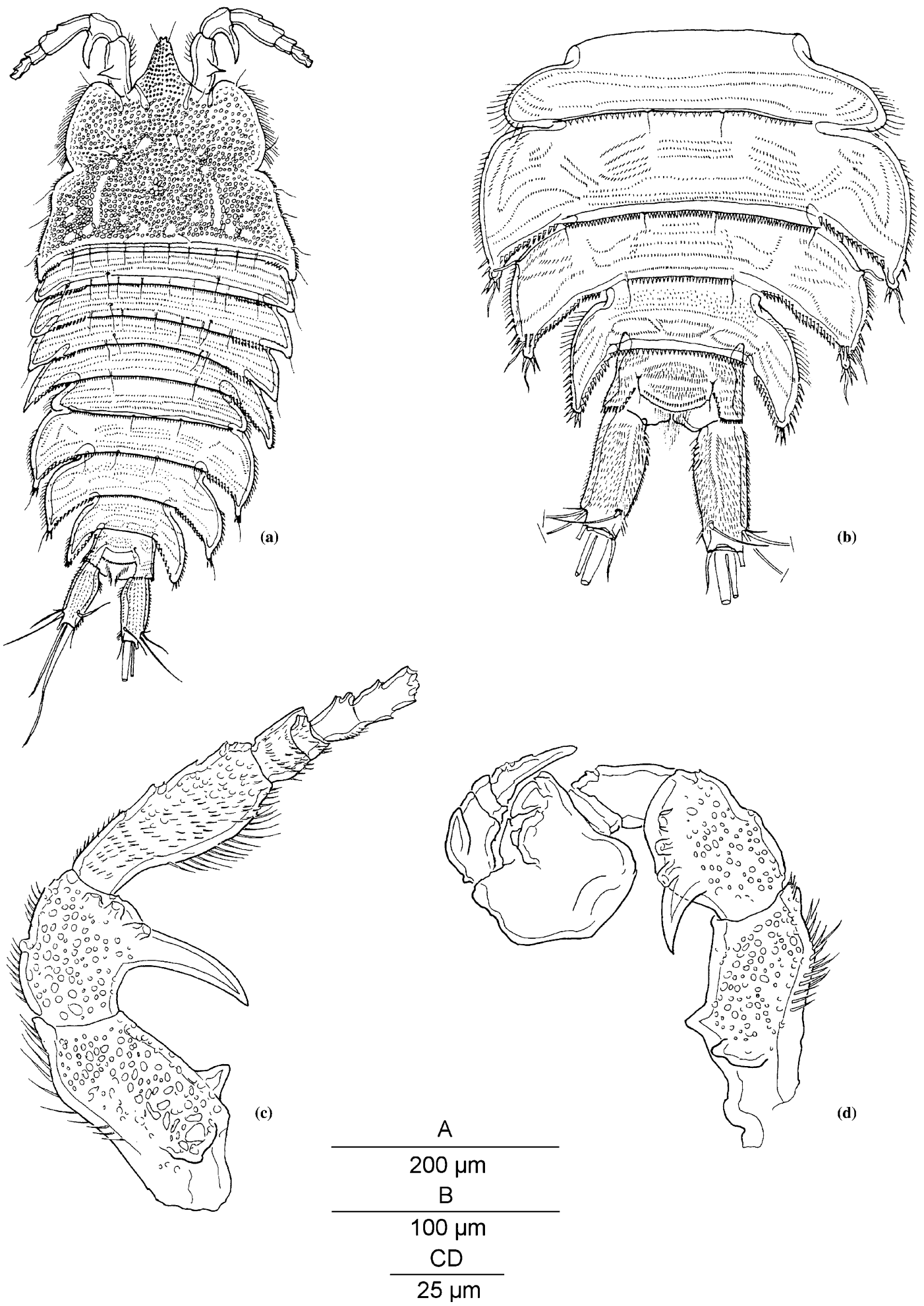

Figure 9. Peltidiphonte maior sp. n. (a) female habitus, dorsal; (b) female urosome, dorsal; (c) female antennule (armature omitted), dorsal; (d) male antennule (armature omitted), dorsal. 

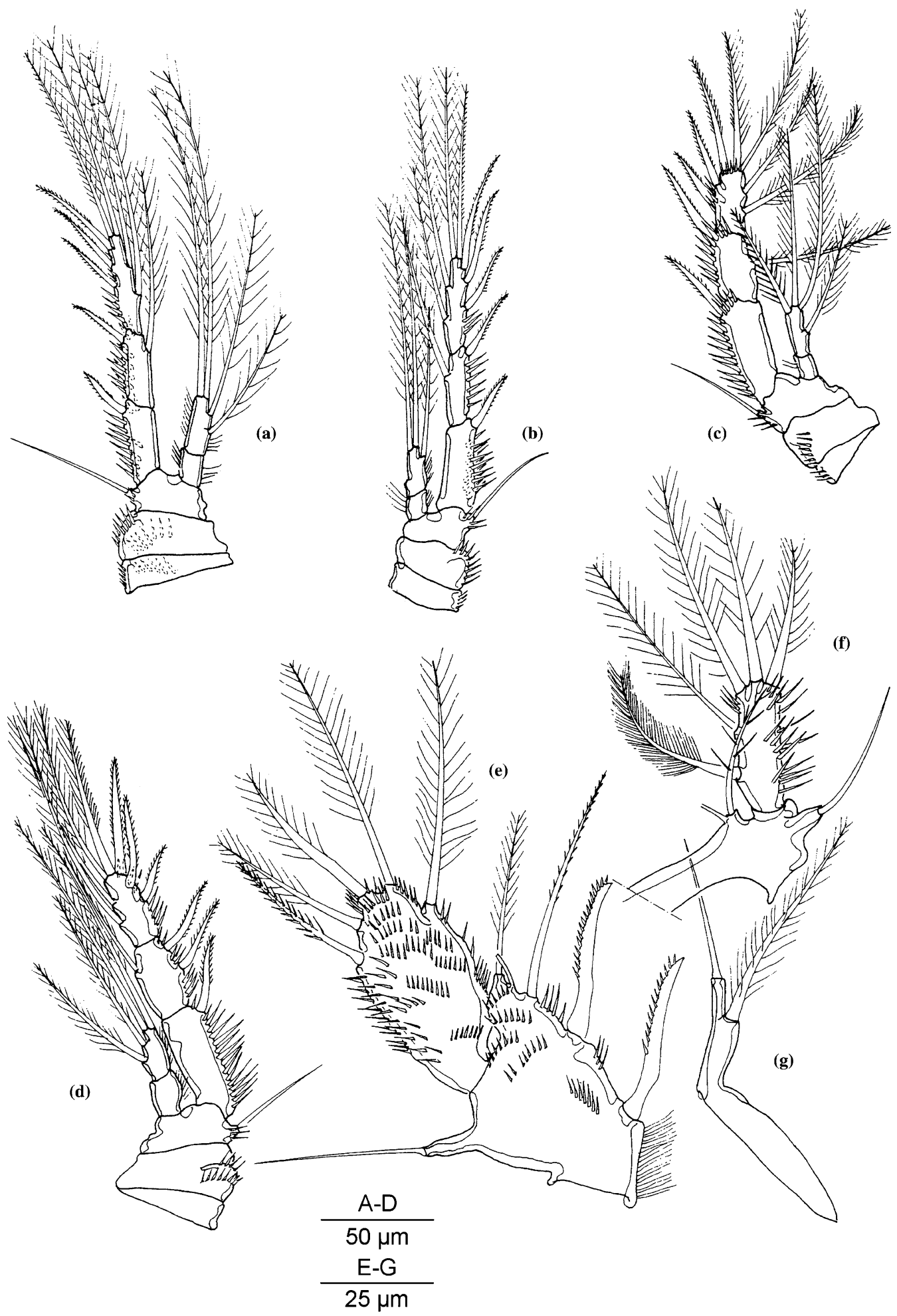

Figure 10. Peltidiphonte maior sp. n. (a) female P3, posterior; (b) female P4, posterior; (c) male P4, anterior; (d) male P3, anterior; (e) female P5, anterior; (f) male P5, anterior; (g) male P6, anterior. 
and exopodite furnished with several rows of spinules.

\section{Description of male}

Total body length $451-590 \mu \mathrm{m}$ (measured from anterior margin of rostrum to posterior margin of caudal rami).

Habitus as in female except for a more slender urosome. Ventral surface of the third urosomite with a transversal median row of spinules. Posteroventral margins of third to fifth urosomites bearing a row of strong spinules.

Antennule (Fig. 9d) eight-segmented; sub-chirocer. Segment 1 and 2 as in female. Segment 6 with a distinct dorsal process.

Mouthparts, P1 and P2 as in female.

Exopodal segments and outer spines of P3 and $\mathrm{P} 4$ more robust than in female (Fig. 10d, c). Outer terminal element on exp-3 rigid. Outer seta of enp2 of $\mathrm{P} 4$ with slightly stronger setules.

P5 (Fig. 10f). Baseoendopod bearing one plumose seta. Exopodite oblong, having long spinules along the outer margin and bearing five plumose setae.

P6 (Fig. 10g) vestiges asymmetrical.

Variability - In the holotype the P2 has 2 inner setae on one side but only 1 inner seta on the other side. The setal formula of this segment is very variable. Specimens with 2 inner setae are as common as specimens with only 1 inner seta. The median exopodal segment of the allotype P3 bears 2 outer spines (Fig. 10d) but has normally 1 outer spine.

Differential diagnosis - Peltidiphonte cristata, $P$. maior, $P$. ovata and $P$. paracristata have swimming legs with the same setal formulae. However, $P$. maior differs from its congeners in several aspects: the shape of the posterolateral angles of the cephalothorax, the length/width-ratio of the caudal rami, the length of the body and the more strongly developed male exopods of P3 and P4.

Known range $-P$. maior is known from the northern coast of Papua New Guinea (Madang Province).

Peltidiphonte morovoensis Gheerardyn \& Fiers sp. n.

Type locality - Western Pacific Ocean, Solomon Islands, Uipi Island, Morovo Lagoon ( $8^{\circ} 29^{\prime} \mathrm{S}$, $\left.158^{\circ} 4^{\prime} \mathrm{E}\right)$, sediments from the reef flat.
Material - (a) From type locality: holotype $ᄋ$ dissected on 2 slides (COP 2443a-b); paratype is 1 o (COP 2444) preserved in 70\% alcohol; collected 2 November 1982;

(b) Western Pacific Ocean, Australia, Queensland, John Brewer Reef ( $\left.18^{\circ} 38^{\prime} \mathrm{S}, 147^{\circ} 4^{\prime} \mathrm{E}\right)$, sediments collected near the basis of the reef, water depth $3 \mathrm{~m}$ - paratypes are 1 o on 1 slide (COP 4668), 1 오 dissected on 2 slides (COP 4667a-b) and 1 (COP 2445) preserved in 70\% alcohol; collected 24 May 1984.

Etymology - The species name refers to the type locality of this species.

\section{Description of female}

Total body length $342-370 \mu \mathrm{m}$ (measured from anterior margin of rostrum to posterior margin of caudal rami). Largest width measured at posterior margin of cephalothorax: $148 \mu \mathrm{m}$.

Rostrum (Fig. 11b) strongly prominent; rather narrow; lateral margins tapering in front; tip bifid; pitted dorsally.

Habitus (Fig. 11a) typical for the genus. Cephalothorax tapering in front and distinctly constricted in the middle. Posterolateral angles of cephalothorax slightly extended and posteriorly directed. Prosomites and urosomites laterally extended. Anterior part of genital double-somite with rounded lateral margins. Posterior part of genital double-somite and following urosomites (except anal somite) with posteriorly directed extensions. Anal operculum convex with a slightly serrate margin.

Integument of cephalothorax and pleurotergites of prosomites and urosomites entirely and densely pitted. Pleural areas of the prosomites less densely pitted. Posterodorsal margin of cephalothorax smooth but distinctly serrate near the lateral extensions. Posterodorsal margins of prosomites and urosomites serrate along the tergital and pleural margin and distinctly serrate along a small convex part near the transition of both plates.

Ventral surface of genital double-somite striated; of the following urosomites smooth. Posteroventral margins of genital double-somite and following urosomites spinulose.

Caudal rami (Fig. 11d) 1.7 times as long as wide; pitted dorsally; smooth ventrally; outer margin straight bearing small spinules; inner 

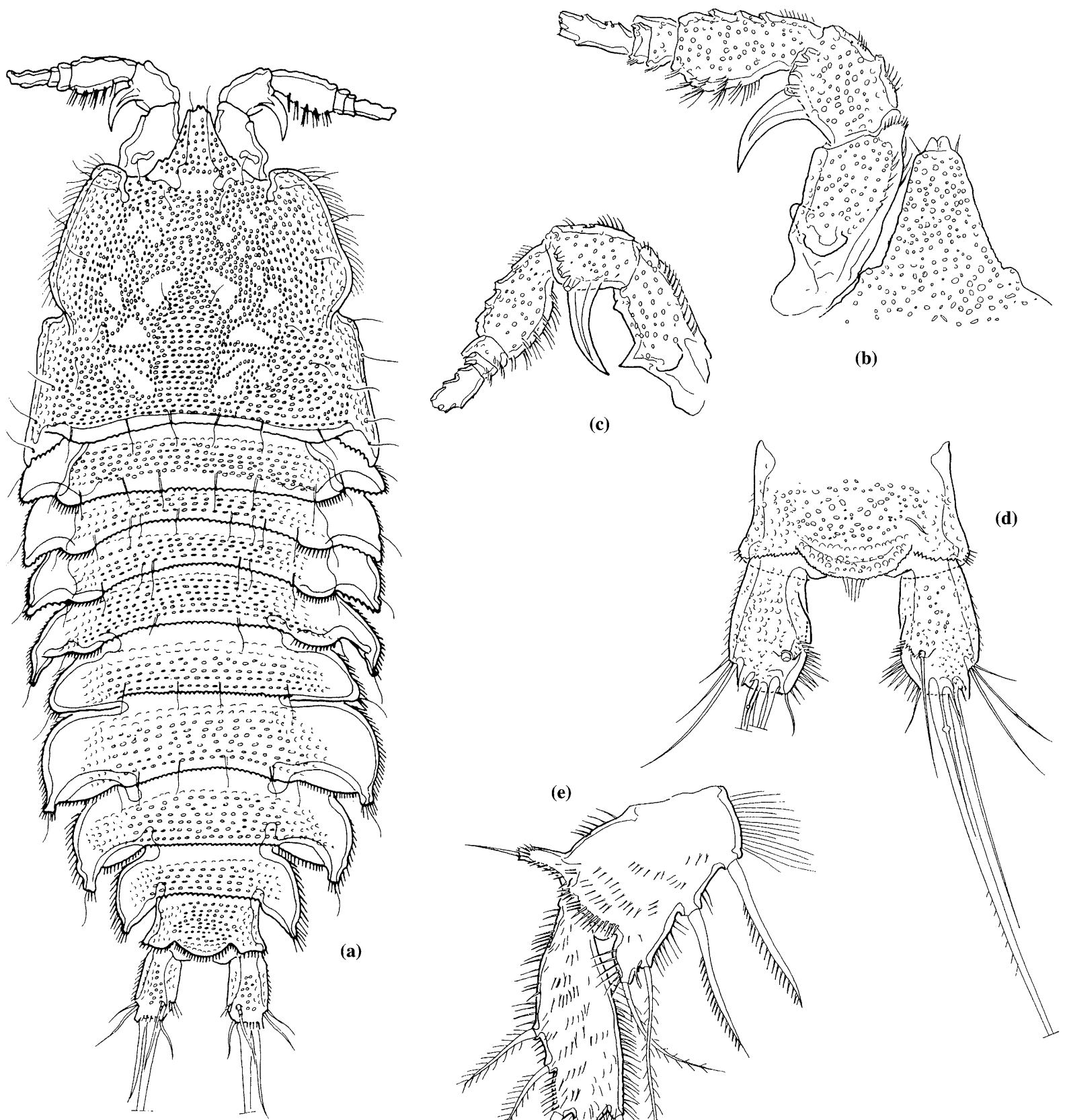

(b)

(c)

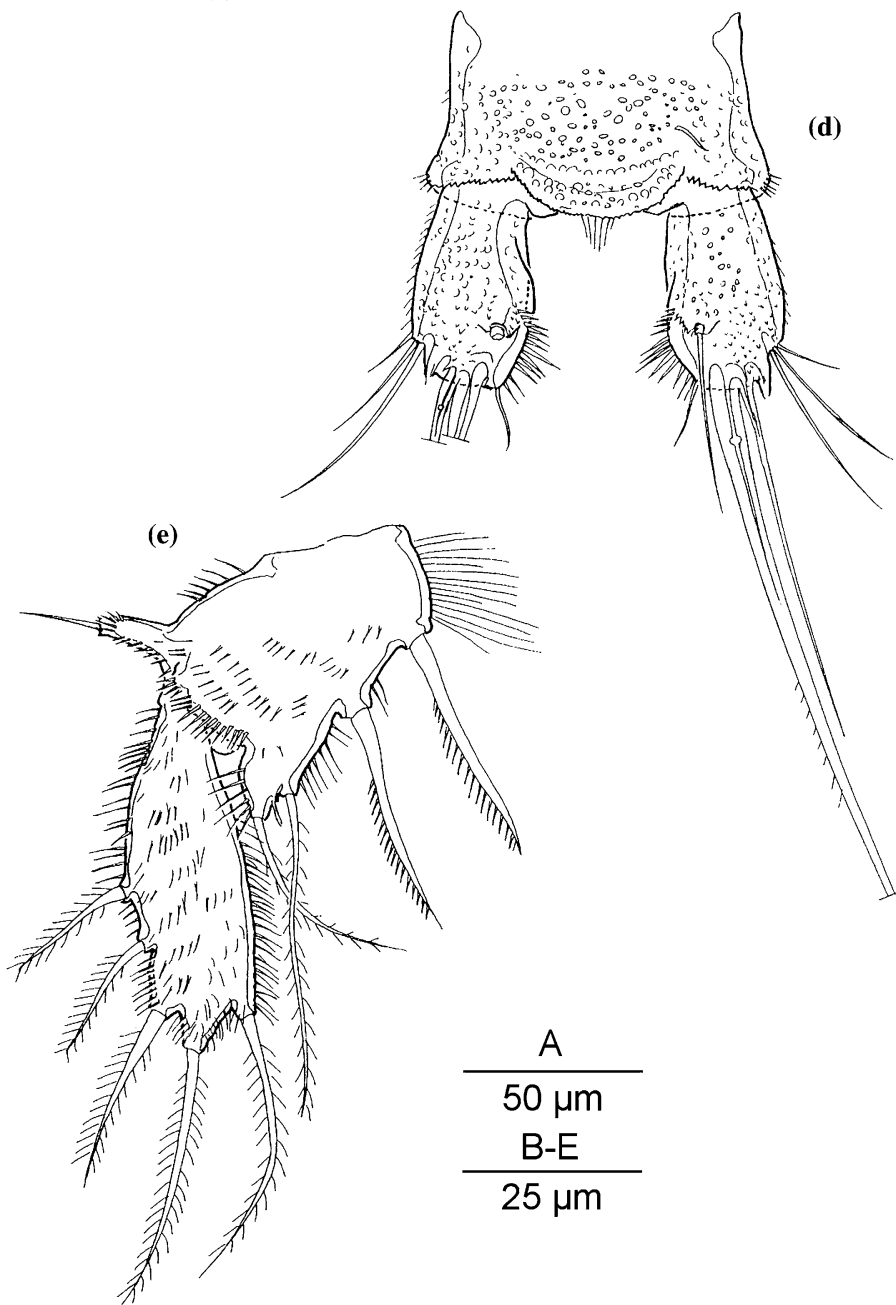

Figure 11. Peltidiphonte morovoensis sp. n. (a) female habitus, dorsal; (b) female antennule (armature omitted) and rostrum, dorsal; (c) female antennule (paratype, armature omitted), dorsal; (d) female caudal rami, dorsal; (e) female P5, anterior. 
margin smooth except for a short transversal row of spinules near the implantation of seta VII; inner margin distally slightly convex, forming dorsally a bump upon which stands seta VII. Seta I, II, III and VII implanted sub-apically.

Antennule (Fig. 11b) six-segmented. Segment 1-4 pitted dorsally. Spinules on the inner margin of segment 1-3 and along the outer margin of segment 3-5. Integument of segment 5 and 6 smooth. Segment 1 proximally with a dorsal and a small lateral blunt thorn. Segment 2 with a long posteriorly directed hook.

Mouthparts and $\mathrm{P} 1-\mathrm{P} 4$ as in Peltidiphonte rostrata. Swimming leg setal formula in Table 1.

P5 (Fig. 11e). Baseoendopodite with long spinules along the proximal inner margin and along the articulation with the exopodite. Baseoendopodite and exopodite covered with spinules. Exopodite elongate.

\section{Description of male}

Total body length $350 \mu \mathrm{m}$ (measured from anterior margin of rostrum to posterior margin of caudal rami).

Habitus as in female; but distinctly slender. Especially the urosome is remarkably slender. Ventral surface of the third urosomite with a tranversal row of spinules. Posteroventral margins of third to fifth urosomite bearing a row of spinules; which are small and slender medially and conspicuous long and strong more laterally.

Antennule eight segmented; sub-chirocer. Segment 1 and 2 as in female.

Mouthparts and P1-P4 as in female.

P5. Baseoendopodite represented as a small strip, bearing one seta. Exopodite oblong bearing five plumose setae.

Variability - The thorn on the outer margin of the first segment of the A1 seems to be variable, namely blunt (Fig. 11b) or sharp (Fig. 11c).

Differential diagnosis - Peltidiphonte morovoensis is one of the species with a reduced chaetotaxy of the endopodites. The male of $P$. morovoensis has a distinctly slender urosome as is the case in P. furcata. Males of both species however are clearly discriminated by the shape and length of the caudal rami. The posterolateral angles of the cephalothorax are distinctly sharp in P. furcata and rather rounded in $P$. morovoensis.
Known range $-P$. morovoensis is known from the Solomon Islands (type locality) and from the Great Barrier Reef.

\section{Peltidiphonte ovata Gheerardyn \& Fiers sp. n.}

Type locality - Egypt, Red Sea, Strait of Tiran, Gordon Reef $\left(27^{\circ} 59^{\prime} \mathrm{N}, 34^{\circ} 27^{\prime} \mathrm{E}\right)$, sand sample, water depth 2-3 m.

Material - (a) From type locality: holotype o dissected on 1 slide (COP 2447); allotype $\hat{\sigma}$ dis-

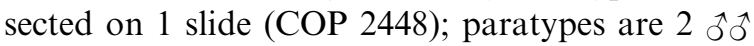
(COP 2449) and $1 \hat{\jmath}$ (COP 4669) preserved in 70\% alcohol; all collected 11 November 1983;

(b) Egypt, Red Sea, Orifa, Ras Umm Sid $\left(27^{\circ} 51^{\prime} \mathrm{N}, 34^{\circ} 17^{\prime} \mathrm{E}\right)$, sand sample, water depth $10 \mathrm{~m}$ - paratype is $1 \hat{\sigma}$ (COP 2446) preserved in 70\% alcohol; collected 11 April 1986;

(d) Western Indian Ocean, different locations along Kenyan coast [Msambweni (4 $28^{\prime} \mathrm{S}$, $\left.39^{\circ} 29^{\prime} \mathrm{E}\right)$, Diani Beach $\left(4^{\circ} 18^{\prime} \mathrm{S}, 39^{\circ} 35^{\prime} \mathrm{E}\right)$, Watamu Marine Park ( $\left.3^{\circ} 21^{\prime} \mathrm{S}, 40^{\circ} 1^{\prime} \mathrm{E}\right)$ ], dead coral fragments and coral sand, water depth from $3 \mathrm{~m}$ to less than $0.5 \mathrm{~m}$ - paratypes are 3 우 and 2 วิธิ dissected on slides (COP 4671 - COP 4675)

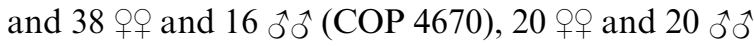
(COP 4676), 1 ô (COP 4677), and 1 q (COP 4678) preserved in $70 \%$ alcohol; collected in February 2002.

Etymology - The species name refers to the body shape of this animal.

\section{Description of female}

Total body length 381-480 $\mu \mathrm{m}$ (measured from anterior margin of rostrum to posterior margin of caudal rami). Largest width measured at posterior margin of cephalothorax: $200 \mu \mathrm{m}$.

Rostrum (Fig. 12g) broad; widening posteriorly; bifid tip with broad lips; rostral tip strongly prominent; dorsally pitted; robust appearance.

Habitus (Fig. 12a). Body ovate in dorsal view. Each somite (except anal somite) laterally extended. Cephalothorax with a distinct constriction near the middle. Anterior part of genital double somite as broad as posterior part.

Cephalothorax and dorsal surface of the caudal rami pitted. Lateral sides of cephalothorax with small denticles. Pleurotergites of prosomites and urosomites with a pattern of small denticles and rows of small denticles. Posterior margin of 


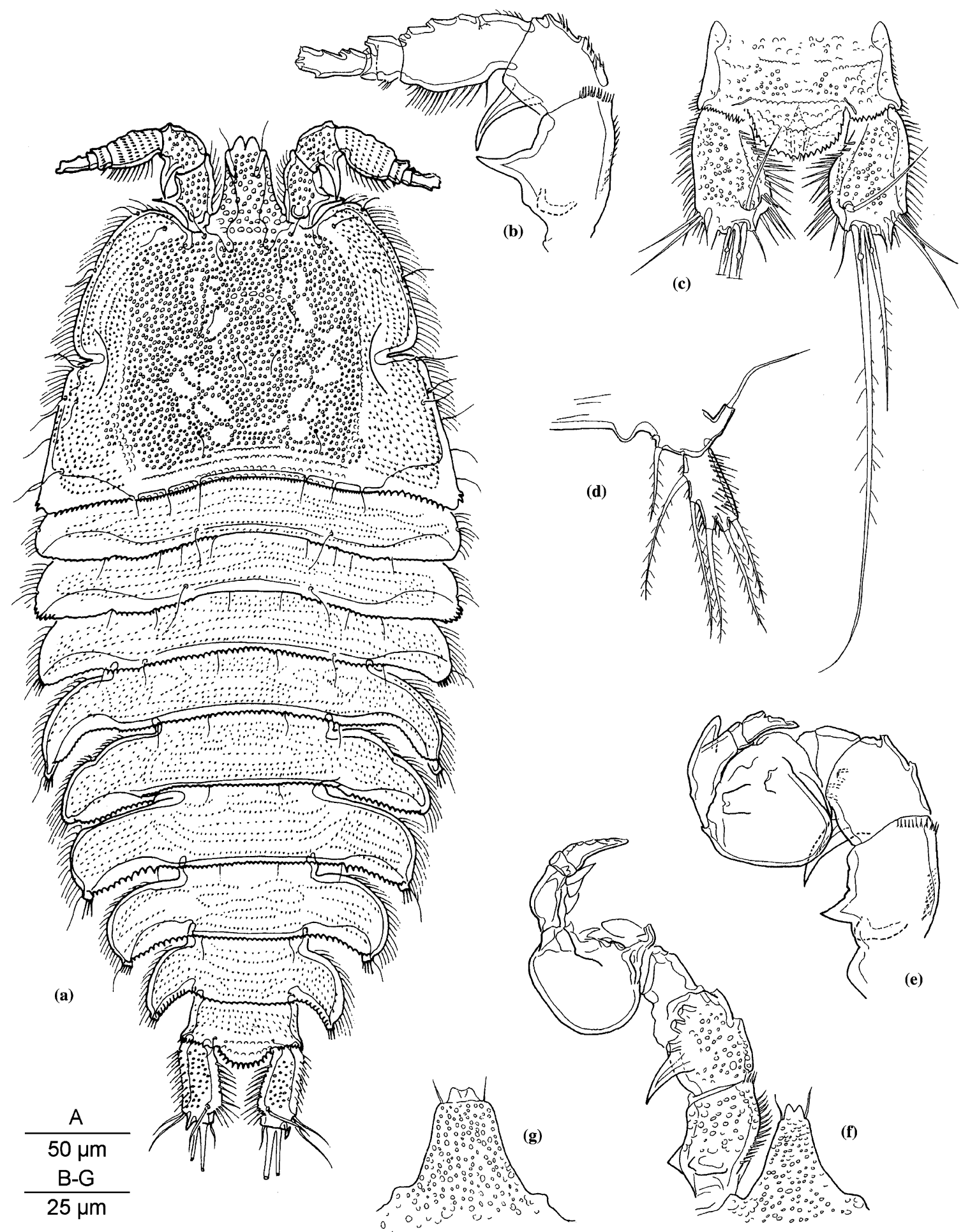

Figure 12. Peltidiphonte ovata sp. n. (a) female habitus, dorsal; (b) female antennule (armature omitted), ventral; (c) female caudal rami, dorsal; (d) male P5, anterior; (e) male antennule (armature omitted), ventral; (f) male antennule and rostrum (paratype, armature omitted), dorsal; (g) female rostrum, dorsal. 
cephalothorax smooth medially and distinctly serrate laterally. Posterior margins of the somites serrate. Posterior margins of the urosomites with larger incisions laterally than medially. Anal operculum distinctly protruding and convex; with a serrate margin and with some pits on the dorsal surface.

Ventral surface of genital double-somite striated; of the following urosomites smooth. Posteroventral margins of the genital double-somite and of the following urosomites spinulose.

Caudal rami (Fig. 12c) 2 times as long as wide with straight outer and convex inner margin. Setae I, II, III and VII implanted sub-apically. Caudal rami pitted dorsally, hairy ventrally. Outer margin of the rami furnished with slender spinules; inner margin with a row of strong spinules.

Antennule (Fig. 12b) six-segmented. Segment 1 and 2 with a pitted dorsal integument. Segment 3 and 4 with rows of small denticles. Segment 5 and 6 smooth. Segment 1 with a blunt thorn dorsally on the proximal half and a large, sharp thorn along the outer margin. Segment 2 with a large posteriorly directed hook.

Mouthparts and $\mathrm{P} 1-\mathrm{P} 4$ as in Peltidiphonte rostrata. Swimming leg setal formula in Table 1.

P5 (Fig. 13a) as in Peltidiphonte rostrata. Proximal outer seta of the exopodite implanted on a distinct bump.

\section{Description of male}

Total body length 326-470 $\mu \mathrm{m}$ (measured from anterior margin of rostrum to posterior margin of caudal rami).

Rostrum (Fig. 12f) less wide as in female.

Habitus as in female, except for a more slender urosome. Transversal row of spinules on ventral surface of the third urosomite. Lateral wing of the second urosomite rounded. Posteroventral margins of third to fifth urosomite with strong spinules.

Antennule (Fig. 12e) eight-segmented; sub-chirocer. Integument of segment 1 and 2 as in female, the other segments smooth. Sharp thorn on outer margin of segment 1 smaller as in female. Segment 6 with a strong blunt process on the outer margin.

Mouthparts and $\mathrm{P} 1-\mathrm{P} 4$ as in female.

P5 (Fig. 12d). Baseoendopodite bearing 1 seta with a tube pore and a bump medially from it. Exopodite oblong with five slender, plumose setae.
Variability - The specimens from the Kenyan coast have shorter caudal rami (1.6 times as long as wide) and a male antennule which has a slightly smaller outer thorn on the first segment and lacks a process on the sixth segment (Fig. 12f).

Differential diagnosis - Peltidiphonte cristata, $P$. maior, $P$. ovata and $P$. paracristata have swimming legs with the same setal formulae. However, $P$. ovata differs from its congeners by the ovate habitus, the robust rostrum, the conspicuous broad anterior part of the genital double-somite, the shape of the caudal rami and the protruding anal operculum.

Known range $-P$. ovata is known from the Red Sea (type region) and the Kenyan coast.

Peltidiphonte paracristata Gheerardyn \& Fiers sp. n.

Type locality - Western Indian Ocean, Kenyan coast, Tiwi Beach $\left(4^{\circ} 14^{\prime} \mathrm{S}, 39^{\circ} 36^{\prime} \mathrm{E}\right)$, dead coral fragments, water depth less than $1 \mathrm{~m}$.

Material - (a) From type locality: holotype 0 on 1 slide (COP 4679); allotype $\hat{\jmath}$ on 1 slide (COP 4680); paratypes are 1 q and $1 \hat{\sigma}$ dissected on slides (COP 4681 - COP 4682); all collected 22 February 2002;

(b) Western Indian Ocean, different locations along the Kenyan coast [Diani Beach $\left(4^{\circ} 18^{\prime} \mathrm{S}\right.$, $\left.39^{\circ} 35^{\prime} \mathrm{E}\right)$, Msambweni (4 $\left.\left.28^{\prime} \mathrm{S}, 39^{\circ} 29^{\prime} \mathrm{E}\right)\right]$, dead coral fragments, water depth $3 \mathrm{~m}$ to less than $0.5 \mathrm{~m}$ - paratypes are 1 q dissected on 2 slides

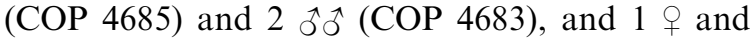
8 ô $\widehat{o}$ (COP 4684) preserved in 70\% alcohol; all collected in February 2002;

(c) Western Indian Ocean, Comoros, different locations on Grande Comore [Moroni $\left(11^{\circ} 42^{\prime} \mathrm{S}\right.$, $\left.43^{\circ} 14^{\prime} \mathrm{E}\right)$, Foumbouni ( $\left.11^{\circ} 51^{\prime} \mathrm{S}, 43^{\circ} 29^{\prime} \mathrm{E}\right)$ ], sand samples, different water depths (11-84 m) paratypes are $2 \hat{\delta} \hat{o}$ and 1 d dissected on slides (COP2430, COP 4687 - COP 4688) and 4 우 and 4

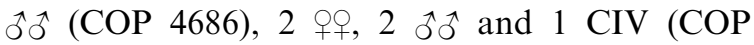

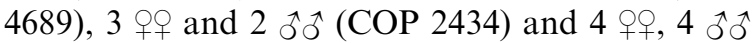
and $1 \mathrm{CV}$ (COP 2435) preserved in 70\% alcohol; all collected in August 1981.

Etymology - The species name refers to the close relationship with Peltidiphonte cristata.

\section{Female}

Total body length 394-531 $\mu \mathrm{m}$ (measured from anterior margin of rostrum to posterior margin of 


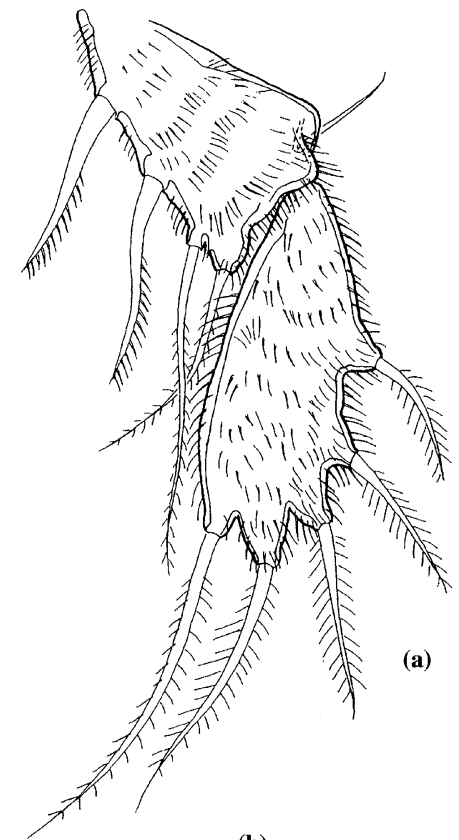

(b)
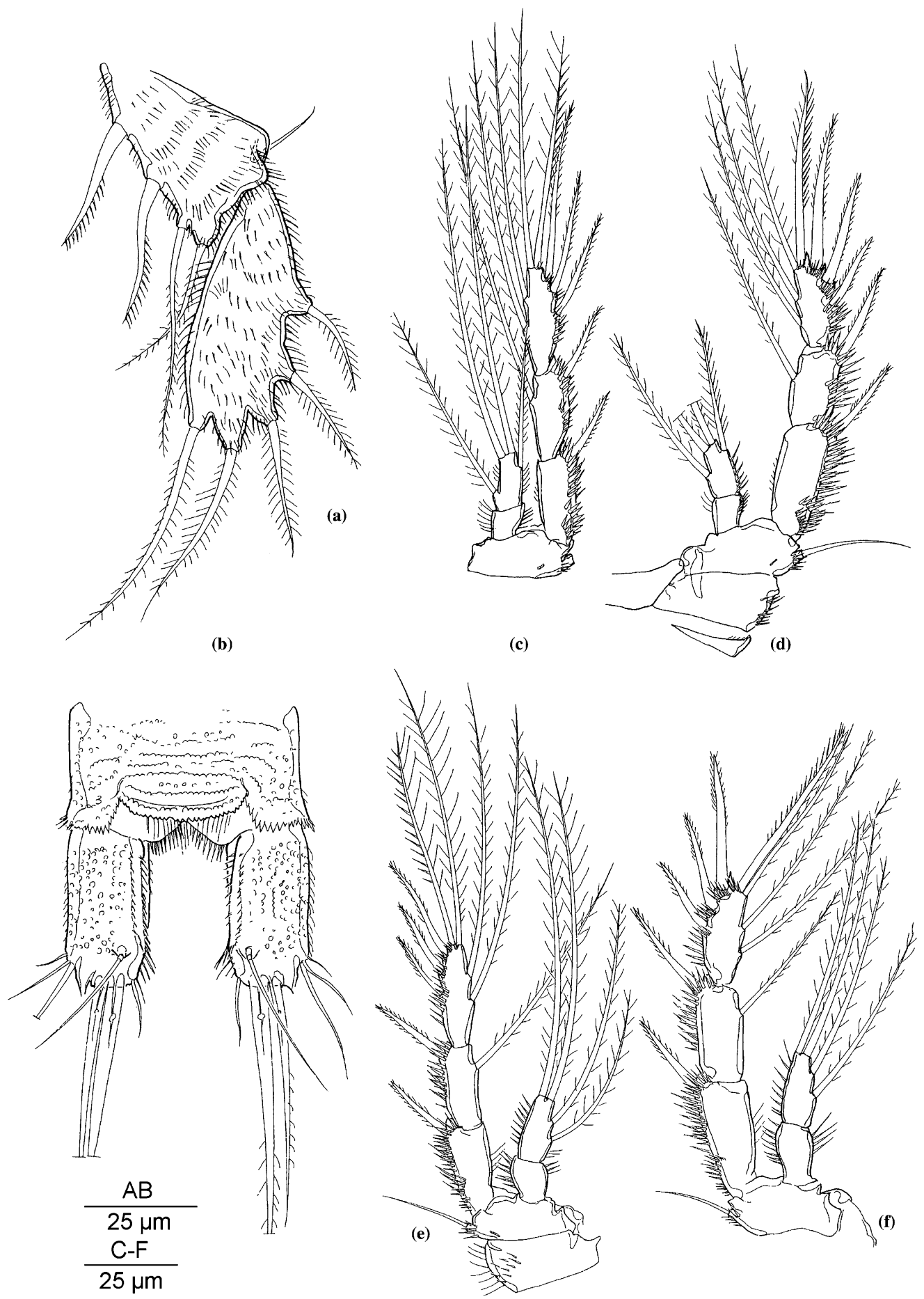

Figure 13. Peltidiphonte ovata sp. n. (a) female P5, anterior; Peltidiphonte paracristata sp. n. (b) female caudal rami, dorsal; (c) female P4, anterior; (d) male P4, anterior; (e) female P3, anterior; (f) male P3, anterior. 
caudal rami). Largest width measured at posterior margin of cephalothorax: $179 \mu \mathrm{m}$.

Caudal rami (Fig. 13b) cylindrical and 2 times as long as wide. Seta I, II, III and VII implanted sub-apically. Inner and outer margin of caudal rami straight; inner margin furnished with two parallel continuous rows of spinules along the entire length.

All other diagnostic features correspond to those encountered in Peltidiphonte cristata sp. $\mathrm{n}$.

\section{Male}

Total body length 366-518 $\mu \mathrm{m}$ (measured from anterior margin of rostrum to posterior margin of caudal rami). Largest width measured at posterior margin of cephalothorax: $160 \mu \mathrm{m}$.

Caudal rami as in female

Exopodal segments and outer spines of P3 and P4 more robust than in female (Fig. 13c-f). Outer terminal element on exp-3 rigid, with a more dense and spinule-like ornamentation along outer side of stem. Outer seta of enp-2 of P4 with slightly stronger setules.

All other diagnostic features correspond to those encountered in Peltidiphonte cristata sp. $\mathrm{n}$.

Differential diagnosis - Peltidiphonte paracristata is closely related to $P$. cristata but clearly differs in the shape of the caudal rami. Moreover the exopodites of P3 and P4 show sexual dimorphism which is an important characteristic.

Known range $-P$. paracristata is known from the Kenyan coast and the Comoros.

\section{Discussion}

Peltidiphonte gen. $\mathrm{n}$. is placed in the family Laophontidae and more specifically in the subfamily Laophontinae T. Scott, 1905 sensu Huys \& Lee, 2000 based on the following synapomorphies as defined by Huys \& Lee (2000): male antennule with up to 3 segments distal to geniculation, mandible uniramous, maxilliped with maximum 2 setae on syncoxa, P1 enp-1 without inner seta, P2 enp-2 without outer spine, proximal outer setae of female P5 exopod with distinctly separated insertion sites and absence of cup-shaped transformed pores on legs or somites.
Peltidiphonte gen. n. is clearly defined by the following combination of apomorphies: the extremely depressed body; the shape of the antennule, bearing two processes on the first segment (one on the dorsal surface and one along the outer margin) and a hook-like process along the outer margin of the second segment; the absence of sexual dimorphism in the endopodites and the absence of an outer seta on enp-2 of P3. Distinction between the species of the new genus is based upon the chaetotaxy of the endopodites, the shape of the rostrum, the number of segments of the antennule, the shape and dimensions of the processes on the first and second segment of the antennule, the shape of P5, the shape of the caudal rami, and the integumental structures on the dorsal surface.

At present, the overall phylogeny of the Laophontidae is poorly understood. Lang's (1948) phylogenetic scheme of the Laophontidae included only 19 genera, six of which being placed in other, existing or new, families since (Huys \& Lee, 2000 and references herein). Moreover, the family has been expanding since, at present containing 63 genera (including that described in this paper) (Huys \& Lee, 2000). The same authors divided the family in two subfamilies and made a thorough phylogenetic analysis of the newly established subfamily of Esolinae Huys \& Lee, 2000. The other subfamily Laophontinae, containing $95 \%$ of the species, also needs a phylogenetic analysis to clarify the relationships between the genera. The present new genus indicates the true diversity of the family is still far from known and its specific habitus illustrates the wide variety of body forms within the family.

The depressed body shape is characteristic for the families Peltidiidae and Porcellidiidae and is also found in certain genera and species of Hamondiidae, Harpacticidae and Thalestridae. Within the Laophontidae, some genera and species (e.g. Asellopsis Brady \& Robertson, 1873, Platylaophonte Bodin, 1968, Applanola hirsuta (Thompson \& A. Scott, 1903)) approach this body shape, but their bodies are not as depressed as in the newly established genus, to which they are not directly related. The depressed and very broadened body shape in Peltidiphonte gen. $\mathrm{n}$. is an important characteristic, which is consistent throughout the 
genus. Peltidiphonte furcata $\mathrm{sp} . \mathrm{n}$. and the male of Peltidiphonte morovoensis sp. n. are not as broad, but show the laterally extended and backwardly produced prosomites and urosomites.

In some harpacticoid genera (e.g. Scutellidium Claus, 1866, Porcellidium Claus, 1860) the dorsoventral flattening of the body is an adaptation to live on the smooth, flat surfaces of macroalgae, decreasing the risk of being swept away by strong water currents impacting on such surfaces (Noodt, 1971; Hicks, 1980). Similarly, the dorsoventral flattening of Peltidiphonte gen. n. is assumed to be an adaptation to life on coral fragments in an environment with strong currents. While in Porcellidium mouthparts and first pereiopod form a ventral sucker that allows attachment to the substrate (Tiemann, 1986), in the new genus the typical P1 and Mxp of the Laophontidae serve as effective grappling hooks to embrace fine microhabitat structures (Hicks, 1980) that can be found in the complex microtopography of dead coral fragments.

Indeed, specimens of Peltidiphonte gen. n. were collected from the washings of large coral fragments and coarse coral gravel. This suggests a close affinity of the new genus with this substrate. However, they were also found in sediment samples. The dorsoventral flattening of Peltidiphonte gen. n. represents an adaptation to an epifaunal lifestyle on the surface of dead coral substrates, but the genus apparently retains the ability to live in the sediment.

The characteristic processes on the first and second segment of the antennule also occur in other genera of the Laophontidae, such as in Amerolaophontina Fiers, 1991, Galapalaophonte Mielke, 1981, Indolaophonte Cottarelli, Saporito \& Puccetti, 1986, Langia Wells \& Rao, 1987, Laophontina Norman \& T. Scott, 1905 and Wellsiphontina Fiers, 1991. These genera have adapted to an endobenthic and interstitial life through their cylindrical body shape and the reduced endopodites and exopodites of the swimming legs. Presumably, the strong structures on the proximal segments of the antennule serve in the locomotion between sand grains. Peltidiphonte gen. n. represents a lineage which retained the characteristic processes on the antennule but became dorsoventrally flattened to live as epifauna.

Apart from the striking resemblance of the antennular morphology in these genera, the ornamentation of the exopodal setae of the antenna appears to be identical. In all laophontid genera having a well developed antennal exopodite the one-segmented ramus bears 4 elements which are either plumose or pinnate. Common to Peltidiphonte gen. $\mathrm{n}$. and the above mentioned genera is that one of the lateral elements (the one inserted on the margin directed towards the abexopodal side) is bare while the 3 other elements have a pinnate appearance. In Peltidiphonte gen. n. the naked seta is rather short (shorter than the other elements) and slender. In contrast, in the genera Laophontina and Galapalaophonte this element is much longer, while it is completely absent in the genera Langia and Indolaophonte.

In the new genus the exopodites of the swimming legs show the complete, conservative setation on the second and third segments, while the endopodites have a rather advanced setation. The outer spine on enp- 2 of P2 is absent as is the case in all laophontinids. Moreover, in the new genus the outer spine on enp- 2 of P3 is also absent. The absence of a sexually dimorph apophysis on the male P3 endopod results from the loss of its homologue (the outer spine on enp-2) in the female. Within the laophontinid genera, which have non-reduced swimming legs with 2-segmented endopods and 3-segmented exopods, the reduction of the outer spine on enp-2 of P3 occurs only in Echinolaophonte Nicholls, 1941 and certain species of Paralaophonte Lang, 1944, Tapholeon Wells, 1967 and Laophonte Philippi, 1840 (e.g. Paralaophonte aenigmaticum Wells, Hicks \& Coull, 1982, Tapholeon ornatus Wells, 1967, Laophonte ifalukensis Vervoort, 1964). Certain species of Peltidiphonte gen. n. further have lost the outer spine on enp-2 of P4.

\section{Distribution}

Peltidiphonte gen. n. has a distribution covering the Indo-West Pacific (Fig. 14). In the course of an extensive study of the family Laophontidae (Fiers, unpublished), samples from different substrates, including washings of algae, interstitial samples in mangroves, sediments, coarse coral sand and gravel, collected in the Caribbean region were also studied. These samples did not reveal any representatives of Peltidiphonte gen. n., implying 


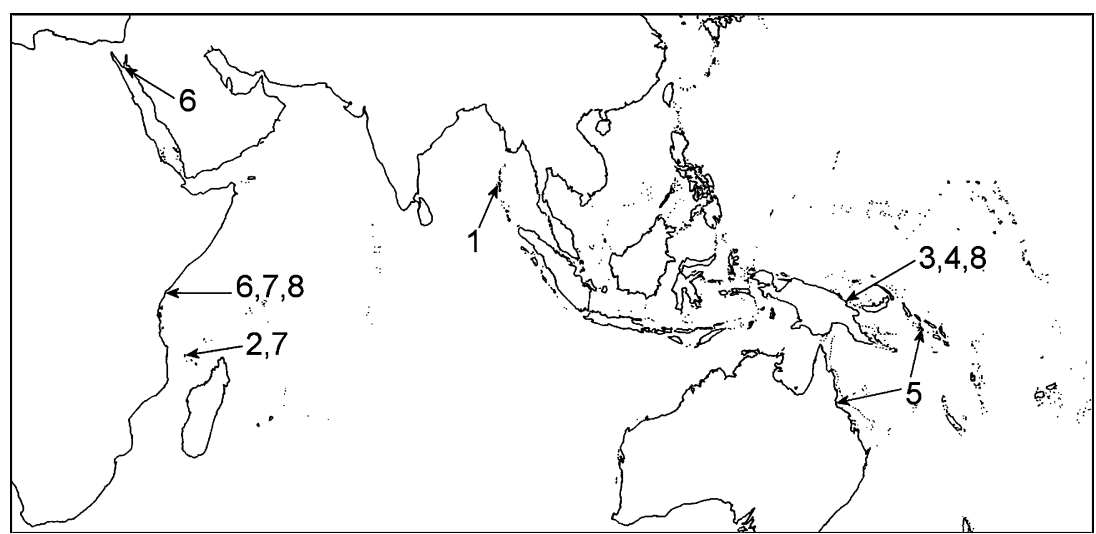

Figure 14. Map of the Indo-West Pacific Ocean showing the sampling locations of the eight presently known Peltidiphonte gen. $\mathrm{n}$. species. (1) Peltidiphonte andamanica sp. n., Andaman Islands; (2) P. cristata sp. n., Comoros; (3) P. furcata sp. n., northern coast of Papua New Guinea; (4) P. maior sp. n., northern coast of Papua New Guinea; (5) P. morovoensis sp. n., Solomon Islands and northeastern coast of Australia; (6) P. ovata sp. n., Kenyan coast and Red Sea; (7) P. paracristata sp. n., Kenyan coast and Comoros; (8) P. rostrata sp. n., Kenyan coast and northern coast of Papua New Guinea.

the absence of this genus in the Caribbean region or the need for more samples of coral fragments.

\section{Acknowledgements}

The first and last author acknowledge funding, as aspirant and postdoctoral fellow, respectively, from the Fund for Scientific Research (FWOFlanders, Belgium). The sampling campaign in Kenya was organised in the frame of the research project G.0199.03 'A comparative study of the meio-epifauna associated with tropical and coldwater coral reefs' sponsored by the Fund for Scientific Research (FWO-Flanders, Belgium). The materials on which this paper is based have been collected in the following regions and by the following persons or groups: Andaman Islands: 1983, W. Wellens \& H. De Brauwer; Comores Islands: 1981, Groupe Plongée de l'Expedition Karthala, 1985, W. Wellens; Kenya : 2002, M. Raes; Papua New Guinea: 1977, 1978, 1981, J. Van Goethem, 1979, J. Pierret, D. Christensen, 1982, K. Wouters; Red Sea: 1983, A. Brauwer \& H. Smedt, 1986, W. Wellens; Solomon Islands: 1982, A. Coomans.

\section{References}

Coull, B. C., 1977. Marine flora and fauna of the northeastern United States. Copepoda: Harpacticoida. NOAA Technical Report. NHFS Circular 399: 1-48.

Hicks, G. R. F., 1980. Structure of phytal harpacticoid copepod assemblages and the influence of habitat complexity and turbidity. Journal of Experimental Marine Biology and Ecology 44: 157-192.

Hicks, G. R. F. \& B. C. Coull, 1983. The ecology of marine meiobenthic harpacticoid copepods. Oceanography and Marine Biology. Annual Review 21: 67-175.

Huys, R. \& G. A. Boxshall, 1991. Copepod Evolution. The Ray Society, 159, London.

Huys, R., J. M. Gee, C. G. Moore \& R. Hamond, 1996. Marine and Brackish Water Harpacticoid Copepods. Part 1. Synopses of the British Fauna (New Series), 51. Field Studies Council, Shrewsbury.

Huys, R. \& W. Lee, 2000. Basal resolution of laophontid phylogeny and the paraphyly of Esola Edwards. Bulletin of the Natural History Museum London, Zoology Series 66: 49-107.

Lang, K., 1948. Monographie der Harpacticiden, I \& II. Håkan Ohlssons Boktryckeri, Lund pp. 1-1683.

Noodt, W., 1971. Ecology of the Copepoda. Smithsonian Contributions to Zoology 76: 97-102.

Tiemann, H., 1986. The functional morphology and histology of the genus Porcellidium (Copepoda, Harpacticoida). Syllogeus 58: 487-493. 